\title{
Medicinal Plants in the Treatment of Depression. II: Evidence from Clinical Trials
}

Authors

Inés Moragrega ${ }^{1}$, José Luis Ríos ${ }^{2}$

Affiliations

1 Departament de Psicobiologia, Facultat de Psicologia, Universitat de València, Valencia, Spain

2 Departament de Farmacologia, Facultat de Farmàcia, Universitat de València, Valencia, Spain

Key words

antidepressant, medicinal plants, clinical trials, natural products, curcumin, saffron

received March 5, 2021

accepted after revision

May 17, 2021

published online

June 22, 2021

Bibliography

Planta Med 2022; 88: 1092-1110

DOI 10.1055/a-1517-6882

ISSN 0032-0943

(C) 2021. Thieme. All rights reserved.

Georg Thieme Verlag KG, Rüdigerstraße 14,

70469 Stuttgart, Germany

Correspondence

Dr. Inés Moragrega

Departament de Psicobiologia, Facultat de Psicologia, Universitat de València

Av. Blasco Ibáñez 21, 46010 Valencia, Spain

Phone: + 34963543304 , Fax: + 34963544943

ines.moragrega@uv.es

Correspondence

Prof. José Luis Ríos

Departament de Farmacologia, Facultat de Farmàcia,

Universitat de València

Av. Vicent Andrés Estellés s/n, 46100 Burjassot,

Valencia, Spain

Phone: + 34963544973 , Fax: + 34963544943

jose.I.rios@uv.es

\section{ABSTRACT}

Depression is a syndrome characterized by deep sadness and the inhibition of psychic functions, sometimes accompanied by neurovegetative disorders, with symptoms of anxiety almost always present. The disease produces alterations in a variety of neural networks and neurotransmission systems, along with a dysfunction of the hypothalamic-pituitary-adrenal axis, which leads to concomitant alterations in the immunological response. Generally, there is a parallel increase in proinflammatory mediators as well as oxidative and nitrosative damage caused by a reduction of antioxidant defenses. In a previous review, we compiled and examined studies of medicinal plants that had been evaluated in preclinical assays, including existing data on 155 species studied and reported as antidepressants or as sources of active principles for treating this condition. This review will thus limit its focus to the 95 clinical trials found in PubMed among the 670 articles on antidepressant-like medicinal plants. To this end, we have reviewed the publications cited in the Cochrane Database of Systematic Reviews, PubMed, and the Science Citation Index from 2000 to 2020 . Our review emphasizes those species that have demonstrated the greatest pharmacological potential when studied for their antidepressant properties in humans through clinical trials. Saffron, turmeric, St. John's wort, ginkgo, kava, and golden root are the most relevant plants that have provided important evidence for the treatment of depression in clinical trials.

\section{Introduction}

The disease known as depression is a syndrome characterized by profound sadness and the inhibition of psychic functions, sometimes accompanied by neurovegetative symptoms. Unipolar depression is a condition characterized by anhedonia (loss of interest or capacity for pleasure), apathy, changes in sleep and appetite, and sadness; under the worst circumstances, it can also provoke suicidal ideation [1]. Stress is the main trigger of depression as it produces a body's reaction towards a stimulus, displayed in the form of a mental, physical, and/or emotional response [2]. In the latest edition of the DSM-5, the essential core of depression is al- 


$\begin{array}{ll}\text { ABBREVIATIONS } \\ \text { 5-HT } & \text { 5-hydroxytriptamine (serotonin) } \\ \text { ACTH } & \text { adrenocorticotropic hormone } \\ \text { AMPK } & \text { 5' adenosine monophosphate-activated protein } \\ & \text { kinase } \\ \text { BDNF } & \text { brain-derived neurotrophic factor } \\ \text { CREB } & \text { cAMP response element binding } \\ \text { CRH } & \text { corticotrophin-releasing hormone } \\ \text { CXCL8 } & \text { interleukin-8 } \\ \text { DA } & \text { dopamine } \\ \text { DSM } & \text { Diagnostic and Statistical Manual } \\ & \text { of Mental Disorders } \\ \text { ERK } & \text { extracellular signal-regulated kinase } \\ \text { GABA } & \text { gamma-aminobutyric acid } \\ \text { GCSF } & \text { granulocyte colony-stimulating factor } \\ \text { HPA } & \text { hypothalamic-pituitary-adrenal } \\ \text { IL } & \text { interleukin } \\ \text { iNOS } & \text { inducible nitric oxide synthase } \\ \text { MAO } & \text { monoamine oxidase } \\ \text { MCP-1 } & \text { monocyte chemotactic protein-1 } \\ & \text { (also known as CCL2) } \\ \text { MDD } & \text { major depressive disorder } \\ \text { NA } & \text { noradrenaline } \\ \text { NMDA } & \text { N-methyl-D-aspartic acid } \\ \text { nNOS } & \text { neuronal nitric oxide synthase } \\ \text { NO } & \text { nitric oxide } \\ \text { Nrf2 } & \text { nuclear factor erythroid 2-like 2 } \\ \text { REM } & \text { rapid eye movement } \\ \text { SSRI } & \text { selective serotonin reuptake inhibitor } \\ \text { TLR4 } & \text { Toll-like receptor-4 } \\ \text { WHO } & \text { World Health Organization } \\ & \end{array}$

ways characterized by sadness, hopelessness, lack of illusion, and anhedonia, although the clinical picture can be widely heterogeneous in course, intensity, and duration [1]. Due to their high prevalence and long evolution in most cases, diseases such as depression and anxiety require a great number of resources and health expenditure, with economic costs in excess of 200 billion dollars per year [3]. Moreover, depression is the main cause of disability worldwide. The latest report from the WHO points out that globally, 264 million people of all ages are suffering from depression [3], and 800000 people die due to suicide every year. Depression is more frequent in women (5.1\%) than men $(3.6 \%)$ and although there are effective treatments for mental disorders, between 76 and $85 \%$ of people in low- and middle-income countries receive no treatment for their disorder. It is well known that depression arises from a complex interaction between biological, social, psychological, and, of course, epigenetic factors. People facing adverse life events are, indeed, more likely to develop a mental disorder, especially depression, so it is not surprising that the incidence of depression has risen dramatically in the past year, with predictions for this year and the next being even worse. The current socio-health situation not only exacerbates mental health problems and impoverishes the population, but it also makes it more difficult to access effective treatments or undertake preventive measures. This fact, along with the interrelationship between depression and physical health, has led to a worrying decrease in public health worldwide; therefore, depression is one of the priorities covered by the WHO's Mental Health Gap Action Programme [4].

Because depression is a multifactorial disorder, its development can depend on different effects that can cause dysfunctions in neural networks and neurotransmission systems. For example, some depressed patients have been shown to suffer a decrease in monoamines and their metabolites, as well as the corresponding transporters and precursors. These findings led to the formulation of the monoaminergic hypothesis of depression, which is the basis for the standard pharmacological treatment of the disease [5]. To date, however, it has not been possible to demonstrate this hypothesis conclusively; although treated patients generally regain their normal mood and behavior, it cannot be said that antidepressants "normalize" brain activity because the brains of patients treated with antidepressants are in a different state than those of people who are not depressed [6]. In addition, various studies have also reported on the existence of a dysfunction of the HPA axis underlying depressive disorders, as well as the role of corticosteroids through the release of the corresponding hormones, such as the $\mathrm{CRH}$ in the paraventricular nucleus of the hypothalamus, the ACTH in the pituitary gland, and cortisol in the adrenal glands [6]. In depressed patients, circulating cortisol is increased, while alterations in the function of glucocorticoid receptors or the deterioration of negative feedback in the HPA axis play a central role in resistance to these hormones [7]. In this sense, various researchers have argued that psychoneuroimmunological dysfunction underlies major depressive disorders, as documented by several studies, which found that depressed patients present alterations in both the peripheral immune system and cellular immunity, as well as elevated levels of proinflammatory mediators [8].

Multiple theories have questioned the monoaminergic hypothesis and tried to explain the biological changes that occur in depression; some of these will be discussed briefly here since they were examined more extensively in a previous review of preclinical studies on the use of medicinal plants in depression [9]. Physiological or psychological conditions that activate the immune system also seem to make patients more susceptible to depression. Therefore, among the explanations regarding the pathophysiology of depression, the relationship between depression and inflammation has emerged as playing a relevant role [10, 11]. Currently, there are at least ten different families of antidepressants used for pharmacological treatment, with their differences not due to their efficacy, but rather to their tolerability profile. Moreover, inflammation probably plays a large role in the response to antidepressant treatment [12]. The presence of high levels of proinflammatory mediators in patients with depression has allowed researchers to establish a clear relationship between depression and inflammation. The symptoms of cytokine-induced depression in patients undergoing immunotherapy do not differ from a major depressive disorder of unknown etiology, and antidepressants may be effective for both. It has been shown that antidepressants decrease the inflammatory response and pro- 
inflammatory factors, such as IL-2, IL-6, TNF- $\alpha$, and interferon- $\gamma$, and that the levels of these mediators are higher more frequently in individuals who do not respond to antidepressant treatment. Moreover, cyclooxygenase-2 inhibitors and TNF antagonists may increase the effects of antidepressant treatments in some people, suggesting the possibility of a subtype of inflammatory depression [13]. All these findings indicate that cytokines seem to contribute to depression, both through their involvement in brain neurotransmission as well as their role in neuroendocrine functions [14-16]. Importantly, changes in brain volume and a reduction in gray matter density have been observed in several areas of the brain in depressed people, namely, the hippocampus, anterior cingulum, left amygdala, and right dorsomedial prefrontal cortex, all of which led to significant alterations in the homeostasis of neural circuitry [17]. In contrast, therapies that focus on provoking plasticity enhancements by promoting BDNF secretion in the brain, e.g., neurogenesis, dendritic branching, and synaptogenesis, have been shown to have antidepressant effects, with an increase in serum being associated with recovery $[18,19]$. These facts reinforce other possible hypotheses, such as the neuroplasticity or neurotrophic hypotheses, as possible explanations for the pathophysiology of depression.

Oxidative and nitrosative damage also cause neurodegeneration, apoptosis, and reduction of neurogenesis and neuronal plasticity, leading to mitochondrial alterations, mitochondrial DNA damage, and a reduction of ATP production [14,20-25]. In the case of the relationship between depression and oxidative stress, some drugs can reduce the increase in markers of oxidative stress while producing a regulated increase in Nrf2, which is involved in the expression of different genes and antioxidant enzymes [20]. In this context, compounds with antioxidant properties could be of interest in the treatment of depression. These include melatonin, which has also demonstrated its ability to reestablish and adjust circadian rhythms, disruptions of which frequently accompany mood disorders [26]. Another example is the phenolic curcumin, which has been shown to regulate NO levels, possibly through the inhibition of iNOS, as well as the activity of nNOS in humans. Since $\mathrm{NO}$ is elevated in patients with major depression, a decrease in these levels could induce antidepressant effects, especially through the modulation exerted by NO on the production of neurotransmitters such as NA, 5-HT, and DA [20]. Consistent with these results, studies have found that the administration of cytokines induces behavioral changes through MAOs, modifying their uptake from the synaptic cleft into presynaptic neurons or modifying the transport, such as serotonin transporter (SERT), selective serotonin reuptake inhibitor (SSRI) or selective serotonin reuptake enhancer (SSRE) [27-29].

Another hypothesis for the pathogenesis of depression is the glutamatergic assumption, which postulates that glutamate signaling in the brain may be responsible for impairing neuroplasticity and that it may actually lead to neuronal death by excitotoxicity processes, if excessive. This theory is supported by the extraordinary clinical antidepressant effects that i.v. infusion of ketamine, an NMDA antagonist, produces in treatment-resistant patients, although this effect is short-lasting. It seems logical that if glutamate plays a role, then the inhibitory neurotransmitter GABA is also involved, both through its action on the neuroendocrine system, and also by exerting neuroprotective effects [30].

Many medicinal plants have been described as potential antidepressant agents [31-37] and a relevant group of them has been tested in animal models with different results. In a previous review [9], we compiled papers published between the years 2000 and 2020 in which these plants were cited as antidepressant-like agents and studied in vivo (using animals) or in vitro for their effects on various biochemical and physiological systems. Some of them have been shown to inhibit the expression of cytokines, while others seem to act directly on monoamines, modifying their expression, metabolism, reuptake, or effect on the target. Others exhibit antioxidant effects that can reduce neuronal alterations and damage. The aim of this review is, thus, to present and discuss the available evidence for the use of medicinal plants as antidepressant agents in clinical trials. Although treatments for depression can be derived from traditional practice and natural plants, the aim should be to establish their efficacy and safety through rigorous clinical trials. This narrative review examines the principal species tested and their possible mechanisms of action against depression as shown in clinical studies, as well as their general potential. It also presents the possibility of using some of them as adjuvants in the treatment of this disease. We have thus compiled all articles written in English since the year 2000 that were cited in the Cochrane Central Register of Controlled Trials, PubMed, and the Web of Science databases. The key words employed for this review were "antidepressant", "medicinal plants", "natural products", and "clinical trials". Our principal focus was on clinical trials that assayed the efficacy of the plants cited as antidepressants in the literature; of these, we selected those plants that had previously been studied in animal experiments with positive results. From the 183 species selected, to the best of our knowledge, only 17 have been subjected to some sort of clinical trial, with 6 offering relevant results and 3 (saffron, turmeric, and St. John's wort) having an extensive and complete description of properties.

In this review, different rating scales for depression are cited. Some are used extensively while others are more specific and were employed only in a limited group of trials. > Table 1 lists the rating scales cited in this text, whereas specific data from the trials are compiled in $\mathbf{~ T a b l e s ~} \mathbf{2}-\mathbf{4}$.

\section{Clinical Trials}

In general, investigations carried out in humans are limited. There are some species with a relevant number of trials, such as saffron, turmeric, and St. John's wort, but in other cases, the studies are small in number and of poor quality. For example, several studies have established the relationship between a higher consumption of green tea [Camellia sinensis (L.) Kuntze, Theaceae] and a lower prevalence of depression [38], but while the species Centella asiatica (L.) Urban. (syn: Hydrocotyle asiatica L., Apiaceae) has appeared in clinical studies on dermatological disorders, there is only one reference to this species as an anxiolytic [39], along with one more concerning cognitive functions [40], with no specific assays performed with regard to its effects on depression. Another species, Clitoria ternatea L. (Leguminosae), appears in many exper- 
- Table 1 Depression rating scales that appear in this review.

\begin{tabular}{l|l|l|}
\hline \multicolumn{2}{|l|}{ Principal Rating Scales for Depression } \\
\hline BDI & The Beck Depression Inventory \\
\hline DSSS & Depression and Somatic Symptom Scale \\
\hline HAM-D & The Hamilton Rating Scale for Depression (also HRSD) \\
\hline HDI & Hamilton Depression Inventory \\
\hline HDRS & Hamilton Depression Rating Scale (also HAM-D) \\
\hline HFRDIS & Hot Flash-Related Daily Interference Scale \\
\hline IDS-SR30 & Inventory of Depressive Symptomatology - \\
\hline MADRS & Melf-rated version \\
\hline Complementary Rating Scales for Depression-Anxiety \\
\hline BAI & Beck Anxiety Inventory \\
\hline CDA & Comorbid Depression-Anxiety \\
\hline CGI/C & Clinical Global Impression Change \\
\hline CGIS & Clinical Global Impression-Severity Scale \\
\hline DASS & Depression, Anxiety and Stress Scale \\
\hline DRSS & Depression Residual Symptom Scale \\
\hline GDS & Geriatric Depression Scale \\
\hline HAMA & Hamilton Anxiety Scores \\
\hline HADS & Hospital Anxiety and Depression Scale \\
\hline KADSS & Kava Anxiety Depression Spectrum Study \\
\hline PSQI & Pittsburgh Sleep Quality Index \\
\hline STAI & Spielberger State-Trait Anxiety Inventory \\
\hline SWLS & Satisfaction With Life Scale \\
\hline
\end{tabular}

imental studies, but no clinical trials of its antidepressant properties have been performed; only its effects on glycemia and antioxidant capacity in healthy subjects have been studied [41].

\section{Crocus sativus L. (Iridaceae)}

In 2018, Shafiee et al. compiled and described the principal reports on the antidepressant and anti-anxiety properties of saffron in both preclinical and clinical studies. They established that a relevant number of clinical trials demonstrated the antidepressant properties of saffron and its constituents, the actions of which can be considered similar to those of standard antidepressant medications such as imipramine, fluoxetine, and citalopram, but with fewer reported side effects [42]. Among reviews of clinical trials, several stand out, including those written by Ulbricht et al. [43], Lopresti and Drummond [44], Tabeshpour et al. [45], and Tóth et al. [46]. In the first review, there is clear evidence of the therapeutic effect of saffron in mild to moderate depression [43]. With the same objective, Lopresti and Drummond carried out a systematic review of the clinical trials, selecting high-quality, randomized, and double-blind studies with placebo or antidepressant controls. They selected six studies in which saffron exhibited antidepressant effects similar to those achieved with standard drugs, estab- lishing that these antidepressant effects are due to saffron's serotonergic, antioxidant, anti-inflammatory, neuroendocrine, and neuroprotective effects. They therefore suggested using saffron to treat mild to moderate depression and proposed further research to elucidate its possible effects in major depression [44]. Recently, Tóth et al. reviewed the literature on randomized, controlled clinical trials in which saffron was compared to a placebo or standard antidepressants. They selected 1 trial for their qualitative analysis; nine were pooled for statistical analysis. This metaanalysis indicated that saffron is a more effective antidepressant than a placebo, with similar effects to those of the standard drugs tested [46]. However, Khaksarian et al. compared the effect of saffron vs. fluoxetine and a placebo and found that there were no significant differences [47].

Several authors studied the antidepressant effects of saffron in different physiopathological cases, such as postpartum depression and depression or anxiety due to pathologies such as type 2 diabetes. The first group included a double-blind, randomized, placebo-controlled trial performed with mothers suffering from mild to moderate postpartum depression who had a maximum score of 29 on the Beck Depression Inventory (BDI)-II (see $>$ Table 1 for depression rating scales). In the case of women treated with saffron, the BDI-II scores decreased, with a final remission of $96 \%$ in the saffron group vs. $43 \%$ in the placebo group [45]. In a similar study, Kashani et al. compared the safety and efficacy of saffron vs. fluoxetine in the treatment of mild to moderate postpartum depression using a double-blind, randomized, clinical trial. Women with mild to moderate postpartum depression who had a high Hamilton Depression Rating Scale (HDRS) score received either saffron or fluoxetine. No significant differences were observed between groups, leading the authors to propose saffron as a safe alternative for improving the symptoms of postpartum depression; however, this clinical trial should be considered a preliminary study due to the limited number of patients involved [48]. These same authors [49] evaluated the efficacy and safety of saffron in cases of major depressive disorder associated with postmenopausal hot flashes. Fifty-six out of sixty patients completed the trial. The two groups, saffron or placebo, were evaluated using both the Hot Flash-Related Daily Interference Scale (HFRDIS) and HDRS. The results showed that saffron is safe and effective for improving hot flashes and depressive symptoms in healthy postmenopausal women, with no relevant side effects. In the case of patients with depression or anxiety due to type 2 diabetes, Milajerdi et al. carried out a double-blind, placebo-controlled, single-center, randomized trial for evaluating 54 subjects with mild to moderate Comorbid Depression-Anxiety (CDA) diagnosed using DSM-IV. The subjects were assessed with the aid of HDRS and Hamilton Anxiety Score (HAMA) measurements, the Pittsburgh Sleep Quality Index (PSQI), and the Satisfaction with Life Scale (SWLS). Participants in the saffron group improved signs of moderate to mild CDA, anxiety, and sleep disturbances, without changes in the placebo group [50]. Other authors used saffron as a food supplement in both an adjunct and a monotherapy. In this case, they studied the clinical symptoms of depression and anxiety in populations and compared the effects of this supplementation vs. pharmacotherapy or a placebo. Under these conditions, a meta-analysis of 23 studies was carried out for establish- 
- Table 2 Relevant clinical studies on saffron.

\begin{tabular}{|c|c|c|c|}
\hline Dose & Protocols & Effects & Ref. \\
\hline $\begin{array}{l}\text { Saffron }(15 \mathrm{mg} \times 2 / \mathrm{d} / 8 \mathrm{wk}) \\
\text { vs. placebo }\end{array}$ & $\begin{array}{l}\text { Mothers with mild to moderate postpartum } \\
\text { depressive disorder ( } n=60 \text { ); double-blind, } \\
\text { randomized, and placebo-controlled trial; } \\
\text { BDI-II }\end{array}$ & $\begin{array}{l}\text { Saffron had a more significant impact on the } \\
\text { BDI-II than placebo. The information collected } \\
\text { by the questionnaires may not be precise. }\end{array}$ & [45] \\
\hline $\begin{array}{l}\text { Saffron }(15 \mathrm{mg} \times 2 / \mathrm{d} / 6 \mathrm{wk}) \\
\text { fluoxetine }(20 \mathrm{mg} \times 2 / \mathrm{d} / 6 \mathrm{wk})\end{array}$ & $\begin{array}{l}\text { Women with mild to moderate postpartum } \\
\text { depression ( } 18 \text { to } 45 \mathrm{yr} \text { old) } n=13 \text { (saffron), } \\
\mathrm{n}=16 \text { (fluoxetine); HDRS }\end{array}$ & $\begin{array}{l}\text { No differences between saffron and positive } \\
\text { control. Limited number of patients. }\end{array}$ & [48] \\
\hline $\begin{array}{l}\text { Saffron }(15 \mathrm{mg} \times 2 / \mathrm{d} / 6 \mathrm{wk}) \text {, } \\
\text { vs. placebo }\end{array}$ & $\begin{array}{l}\text { MDD associated with post-menopausal hot } \\
\text { flashes }(n=56) \text {; HFRDIS, HDRS }\end{array}$ & $\begin{array}{l}\text { Saffron is safe and effective, improving hot } \\
\text { flashes and depressive symptoms. }\end{array}$ & [49] \\
\hline $\begin{array}{l}\text { Saffron, } 30 \mathrm{mg} / \mathrm{d} / 8 \mathrm{wk} \\
\text { vs. placebo }\end{array}$ & $\begin{array}{l}\text { Patients with mild to moderate depression or } \\
\text { anxiety associated to type } 2 \text { diabetes; double- } \\
\text { blind, placebo-controlled, single-center, } \\
\text { and randomized trial ( } n=54 \text { ); CDA, DSM-IV, } \\
\text { HAM-D, HAMA, PSQI, SWLS }\end{array}$ & $\begin{array}{l}\text { Participants passed from mild to moderate } \\
\text { CDA. No changes observed in placebo group. }\end{array}$ & [50] \\
\hline Saffron (50 mg $\times 2 / d / 12 w k$ ) & $\begin{array}{l}\text { Patients with anxiety and depression. } \\
\text { Double-blind, placebo-controlled trial } \\
(n=60) \text {; BAI, BDI }\end{array}$ & $\begin{array}{l}\text { Saffron is effective for mild to moderate } \\
\text { mixed anxiety and depression. Limitations: } \\
\text { single dose of saffron, minor sample size, } \\
\text { and the temporary follow-up. }\end{array}$ & [52] \\
\hline $\begin{array}{l}\text { Saffron }(30-100 \mathrm{mg} / \mathrm{d} / \\
6-12 \text { wk) vs. placebo, } \\
\text { fluoxetine, imipramine, } \\
\text { or citalopram }\end{array}$ & $\begin{array}{l}\text { Meta-analysis with seven studies, } \\
\text { patients with MDD; DSM-IV }\end{array}$ & $\begin{array}{l}\text { Saffron was effective in the treatment of MDD } \\
\text { with comparable efficacy to synthetic anti- } \\
\text { depressants. Saffron was also safe without } \\
\text { serious adverse events reported. }\end{array}$ & [54] \\
\hline $\begin{array}{l}\text { Saffron, }(30 \mathrm{mg} / \mathrm{d} \text { plus fluoxe- } \\
\text { tine, } 20 \mathrm{mg} / \mathrm{d}) \text { vs. control } \\
\text { group with only fluoxetine } \\
(20 \mathrm{mg} / \mathrm{d}), 4 \mathrm{wk}\end{array}$ & $\begin{array}{l}\text { Randomized and double-blind clinical trial of } \\
\text { patients diagnosed with severe depression } \\
(n=40), 15 \text { males and } 25 \text { females }\end{array}$ & $\begin{array}{l}\text { Saffron could be positive in the treatment of } \\
\text { depression and homocysteinemia in patients. }\end{array}$ & [55] \\
\hline
\end{tabular}

ing the antidepressant effect of saffron. The authors concluded that the supplementation of food with saffron could be an effective intervention for symptoms of depression and anxiety [51]. Mazidi et al. analyzed the effects of an extract of saffron on 60 adults with anxiety and depression vs. a placebo in a doubleblind, placebo-controlled trial design using the Beck Anxiety Inventory (BAI) and BDI questionnaires at baseline. Fifty-four subjects completed the trial. The authors observed that saffron modified the BAI and BDI scores of subjects taking saffron vs. a placebo while side effects were rare [52].

Leone et al. reviewed all the clinical studies on saffron published up until 2018 and observed that the hydroalcoholic extract improved mild and moderate depression. They also reported that crocin (30 mg/d, $4 \mathrm{wk}$ ) improved the mood of patients with MDD. Using the same dose but double the amount of time also reduced the symptoms of depression in patients with metabolic syndrome. In this review, the authors attributed the antidepressant properties of saffron to its principal compounds, safranal and crocin ( $\vee$ Fig. 1), because these compounds inhibit the neuronal reuptake of DA, NA, and 5-HT, and also inhibit MAO activity. In this case, crocin is the active compound, acting as a noncompetitive inhibitor of the human enzymes MAO-A and MAO-B in a $\mu \mathrm{M}$ range by binding to their allosteric sites. These authors also reported that crocin $(30 \mathrm{mg} / \mathrm{d}, 4 \mathrm{wk})$ improved the mood of patients with MDD. While the number of studies and trials is quite limited, some of them are definitely of interest [53].
In the case of MDD, in addition to Leone's assay [53], other studies have been conducted. For example, Yang et al. analyzed the efficacy and safety of saffron vs. a placebo or synthetic antidepressants in the treatment of MDD, reviewing 7 studies in a meta-analysis (from 182 records identified in the first revision). In the primary outcome (a change in scores for depressive symptoms compared to baseline), saffron showed more improvements in symptoms of depression than a placebo, exhibiting an efficacy comparable to that of synthetic antidepressants. After evaluating the treatment, dosage, and duration, the authors established that there were no differences in remission, response, or dropout rates, and concluded that saffron is as effective in the treatment of MDD as synthetic antidepressants, but with no adverse events [54]. In what could be considered a complementary study, Jelodar et al. evaluated the correlation between hyperhomocysteinemia and depression by studying the effect of the coadministration of saffron and fluoxetine on plasma homocysteine and its effect on major depression. In a randomized, double-blind clinical trial of patients diagnosed with severe depression, one group received fluoxetine plus saffron whereas the control group received only fluoxetine. At the end of the trial, there was a significant reduction in homocysteinemia in both sexes in the saffron group compared to pretreatment values; however, no significant changes were observed in the control group. The authors thus concluded that saffron could be effective in treating depression and homocys- 
- Table 3 Relevant clinical trials on curcumin as an antidepressant.

\begin{tabular}{|c|c|c|c|}
\hline Dose & Protocols & Effects & Ref. \\
\hline $\begin{array}{l}\text { Curcumin }(1 \mathrm{~g} / \mathrm{d} / 30 \mathrm{~d}) \text { vs. placebo after } \\
\text { a washout interval of } 2 \mathrm{wk} \text {, each subject } \\
\text { was crossed over to the alternative } \\
\text { regimen for a further } 30 \mathrm{~d}\end{array}$ & $\begin{array}{l}\text { Randomized, double-blind, } \\
\text { crossover clinical trial, obese } \\
\text { subjects }(n=30) \text {; BAI, BDI }\end{array}$ & BAI score reduced, BDI scales was not modified. & [58] \\
\hline $\begin{array}{l}\text { Curcumin ( } 500 \mathrm{mg} / \mathrm{d} \text {, for } 5 \mathrm{wk} \text { ) } \\
\text { vs. escitalopram or venlafaxine }\end{array}$ & $\begin{array}{l}\text { Randomized, double-blind, } \\
\text { placebo-controlled pilot study } \\
\text { against placebo ( } n=40) \text {; CGIS, } \\
\text { HDRS (HAM-D), MADRS }\end{array}$ & $\begin{array}{l}\text { Significant positive changes in both groups in all } \\
\text { scales. No differences vs. placebo, but the cur- } \\
\text { cumin group had faster alleviation from depres- } \\
\text { sive symptoms than placebo. }\end{array}$ & [59] \\
\hline $\begin{array}{l}\text { Curcumin }(500 \mathrm{mg} \times 2 / \mathrm{d} / 8 \mathrm{wk} \\
\text { vs. placebo }\end{array}$ & $\begin{array}{l}\text { MDD patients }(n=56) \text {; IDS-SR30 } \\
\text { and STAI scales }\end{array}$ & $\begin{array}{l}\text { Improving the symptoms related to mood, } \\
\text { particularly in patients with atypical depression. }\end{array}$ & [60] \\
\hline $\begin{array}{l}\text { Curcumin }(1000 \mathrm{mg} / \mathrm{d}) \text {, fluoxetine } \\
(20 \mathrm{mg} / \text { day), and the combination } \\
\text { of both }(1000 \text { and } 20 \mathrm{mg} / \mathrm{d} \text { of each) }\end{array}$ & Randomized controlled trial & $\begin{array}{l}\text { The decrease in depressive symptoms of the } \\
\text { combination of fluoxetine and curcumin reached } \\
78 \text { vs. } 65 \% \text { fluoxetine and } 63 \% \text { of curcumin } \\
\text { alone. }\end{array}$ & [61] \\
\hline $\begin{array}{l}\text { Curcumin }(500 \mathrm{mg} \times 2 / \mathrm{d} / 8 \mathrm{wk}) \\
\text { vs. placebo }\end{array}$ & $\begin{array}{l}\text { Randomized, double-blind, } \\
\text { placebo-controlled study } \\
\text { ( } \mathrm{n}=50), 18 \text { to } 65 \mathrm{yr} \text { old with } \\
\text { MDD; IDS-SR30 }\end{array}$ & $\begin{array}{l}\text { Depressive symptoms were reduced. Curcumin } \\
\text { may enhance the sensitivity of endothelin-1 or } \\
\text { leptin receptors, or some other mechanism } \\
\text { associated with biomarkers that have anti- } \\
\text { depressant effects. }\end{array}$ & [62] \\
\hline $\begin{array}{l}\text { Curcumin }(1500 \mathrm{mg} / \mathrm{d} / 12 \text { to } 16 \mathrm{wk} \text { ), } \\
\text { vs. placebo; all patients treated simulta- } \\
\text { neously with their own standard medi- } \\
\text { cation }\end{array}$ & $\begin{array}{l}\text { Double-blind, randomized, con- } \\
\text { trolled against placebo }(n=65) \text {, } \\
\text { MDD established; MADRS and } \\
\text { HAM-D }\end{array}$ & $\begin{array}{l}\text { Curcumin was more effective than placebo, im- } \\
\text { proving MADRS score in the } 12 \text { th and } 16 \text { th wk. } \\
\text { Effects more pronounced in men than in women. }\end{array}$ & [64] \\
\hline $\begin{array}{l}\text { Curcumin }(1000 \mathrm{mg} / \text { day }+10 \mathrm{mg} \\
\text { piperine/d) or antidepressant standard } \\
\text { therapy alone (fluoxetine } 20 \mathrm{mg} / \mathrm{d}), 6 \mathrm{wk}\end{array}$ & $\begin{array}{l}\text { Open-label study }(n=111) \\
\text { HADS }\end{array}$ & $\begin{array}{l}\text { Significant reductions in anxiety and depression } \\
\text { in patients treated with curcumin/piperine vs. } \\
\text { control. }\end{array}$ & [65] \\
\hline $\begin{array}{l}\text { Curcumin and saffron vs. placebo, } \\
\text { curcumin }(250 \mathrm{mg} \times 2),(500 \mathrm{mg} \times 2) \text {, } \\
\text { and curcumin }(250 \mathrm{mg} \times 2) \text { plus saffron } \\
(15 \mathrm{mg} \times 2), 12 \mathrm{wk}\end{array}$ & $\begin{array}{l}\text { Randomized, double-blind, } \\
\text { placebo-controlled study, } \\
\text { patients with MDD, ( } n=123) \text {; } \\
\text { IDS-SR30 (depression) and STAI } \\
\text { (anxiety). }\end{array}$ & $\begin{array}{l}\text { Major improvements in depressive and anxiety- } \\
\text { state symptoms vs. placebo. More effective in } \\
\text { patients with atypical depression ( } 65 \text { vs. } 35 \% \text { ). }\end{array}$ & [67] \\
\hline Curcumin (1000 mg/d/6 wk) vs. placebo & $\begin{array}{l}\text { Adult men } 31 \text { to } 59 \text { yr old with } \\
\text { MDD diagnosed ( } n=108) \text {; } \\
\text { HDRS- } 17 \text { and MADRS scores }\end{array}$ & $\begin{array}{l}\text { Curcumin reduced both scores after } 6 \text { weeks, } \\
\text { and reduced IL- } 1 \beta \text {, TNF- } \alpha \text {, and salivary cortisol } \\
\text { levels and increase plasma levels of BDNF. }\end{array}$ & [18] \\
\hline
\end{tabular}

teinemia in patients with major depression [55]. The details of the experimental data are compiled in $>$ Table 2.

\section{Curcuma longa L. (Zingiberaceae)}

In the case of turmeric, the clinical assays were performed with its major principle, curcumin ( $\bullet$ Fig. 1), which was studied in different trials in humans. Many of these have been summarized in previous reviews. For example, studies prior to 2010 were compiled by Dowlati et al. in a review of the clinical trials carried out to that date. Of those, 24 were published between 1997 and 2008. In the review, Dowlati et al. collected 24 clinical trials involving 1383 individuals in all. Of these, 767 were patients diagnosed with depression using various evaluation scales, but mainly the DSM and Hamilton Depression Rating (HAM-D) [56]. Lopresti and his group compiled trials published up until 2016 that analyzed the anti-inflammatory effects of cognitive behavioral therapy in people with depression and other medical diseases. In this case, the authors reviewed 23 studies involving 1942 patients undergoing cognitive behavioral therapy and proposed to highlight the potential benefits of examining the interrelationship of this therapy on physiological processes implicated in depression, such as inflammation [57]. In another randomized, double blind, crossover clinical trial, 30 obese subjects received curcumin or a placebo. During the trial period, the BAI scores were significantly reduced following curcumin therapy, but the BDI scales remained unmodified [58].

In subsequent studies, various authors used different protocols to determine the efficacy of curcumin as a potential antidepressant agent. Thus, Bergman et al. carried out a randomized, double-blind, placebo-controlled pilot study using the Clinical Global Impression-Severity Scale (CGIS), HDRS, and the Montgomery-Åsberg Depression Rating Scale (MADRS). Although the authors observed significant positive changes on all scales in both groups, the curcumin group experienced faster relief from depressive symptoms than the placebo group [59]. In another study conducted on 56 patients with MDD, treatment with curcumin was significantly more effective than a placebo, improving the 
- Table 4 Relevant clinical studies on St. John's wort.

\begin{tabular}{|c|c|c|c|}
\hline Dose & Meta-analysis/systematic reviews & Effects & Ref. \\
\hline $\begin{array}{l}\text { St. John's wort ( } 240 \text { to } 1800 \mathrm{mg} / \mathrm{d} \text { ) vs. imipramine } \\
\text { ( } 50 \text { to } 150 \mathrm{mg} / \mathrm{d}) \text {, fluoxetine ( } 20 \text { to } 40 \mathrm{mg} / \mathrm{d}) \text {, } \\
\text { sertraline }(75 \text { to } 150 \mathrm{mg} / \mathrm{d}) \text {, amitriptyline ( } 30 \text { and } \\
75 \mathrm{mg} / \mathrm{d}) \text {, maprotiline }(75 \mathrm{mg} / \mathrm{d}) \text {, placebo }\end{array}$ & $\begin{array}{l}\text { Randomized, double-blind clinical } \\
\text { trial of patients diagnosed with } \\
\text { depression, } 27 \text { trials }(n=2291 \text { ) }\end{array}$ & $\begin{array}{l}\text { St. John's wort is more effective than } \\
\text { placebo for the short-term treat- } \\
\text { ment of mild to moderate depres- } \\
\text { sive disorders. }\end{array}$ & [91] \\
\hline $\begin{array}{l}\text { LI } 160 \text { extract ( } 240 \text { to } 1800 \mathrm{mg} / \mathrm{d}) \text { vs. imipramine } \\
(50 \text { to } 150 \mathrm{mg} / \mathrm{d}) \text {, fluoxetine ( } 20 \text { to } 40 \mathrm{mg} / \mathrm{d}) \text {, } \\
\text { sertraline }(75 \text { to } 150 \mathrm{mg} / \mathrm{d}) \text {, amitriptyline }(30 \text { and } \\
75 \mathrm{mg} / \mathrm{d}) \text {, maprotiline }(75 \mathrm{mg} / \mathrm{d}) \text {, placebo }\end{array}$ & $\begin{array}{l}\text { Randomized, double-blind clinical } \\
\text { trial of patients diagnosed with } \\
\text { depression, } 25 \text { trials }(n=3320 \text { ) }\end{array}$ & $\begin{array}{l}\text { Results with St. John's wort extracts } \\
\text { and standard antidepressants were } \\
\text { statistically homogeneous. }\end{array}$ & [92] \\
\hline $\begin{array}{l}\text { St. John's wort ( } 240 \text { to } 1800 \mathrm{mg} / \mathrm{d}) \text { vs. fluoxetine } \\
\text { ( } 20 \text { to } 40 \mathrm{mg} / \mathrm{d}) \text {, sertraline }(50 \text { to } 100 \mathrm{mg} / \mathrm{d}) \text {, } \\
\text { imipramine }(100 \text { to } 150 \mathrm{mg} / \mathrm{d}) \text {, citalopram } \\
(20 \mathrm{mg} / \mathrm{d}) \text {, paroxetine }(20 \text { to } 40 \mathrm{mg} / \mathrm{d}) \text {, amitripty- } \\
\text { line }(75 \mathrm{mg} / \mathrm{d}) \text {, maprotiline }(75 \mathrm{mg} / \mathrm{d}) \text {, placebo }\end{array}$ & $\begin{array}{l}\text { Randomized, double-blind clinical } \\
\text { trial of patients diagnosed with } \\
\text { depression, } 29 \text { trials }(n=5489)\end{array}$ & $\begin{array}{l}\text { St. John's wort had more major } \\
\text { effects than placebo in MDD } \\
\text { patients, and similar effects than } \\
\text { standard antidepressants, but less } \\
\text { side. }\end{array}$ & [93] \\
\hline $\begin{array}{l}\text { Standard extracts: WS5570 (900 mg/d), LI-160 } \\
\text { ( } 20-900 \mathrm{mg} / \mathrm{d}) \text {, STW3 (612-900 mg/d), Ze117 } \\
(500 \mathrm{mg} / \mathrm{d}), \text { LoHyp-57 ( } 800 \mathrm{mg} / \mathrm{d}) \text {, iperisan } \\
(900 \mathrm{mg} / \mathrm{d}) \text {, vs. fluoxetine }(20-40 \mathrm{mg} / \mathrm{d}) \text {, sertra- } \\
\text { line }(50-100 \mathrm{mg} / \mathrm{d}) \text {, imipramine }(100-150 \mathrm{mg} / \mathrm{d}) \text {, } \\
\text { citalopram }(20 \mathrm{mg} / \mathrm{d}) \text {, paroxetine }(20-40 \mathrm{mg} / \mathrm{d}) \text {, } \\
\text { placebo }\end{array}$ & $\begin{array}{l}\text { Meta-analysis of } 13 \text { controlled } \\
\text { clinical trials of patients with mild } \\
\text { to severe depression }(n=1671) \text {; } \\
\text { DSM-IV, ICD-10 HAMD }\end{array}$ & $\begin{array}{l}\text { Efficacy and adverse events in MDD } \\
\text { of St. John's wort are similar to } \\
\text { standard drugs. }\end{array}$ & [94] \\
\hline $\begin{array}{l}\text { Standard extracts: calmigen }(300 \mathrm{mg} / \mathrm{d}) \text {, LI-160 } \\
(600-900 \mathrm{mg} / \mathrm{d}), \text { SJW }(600-900 \mathrm{mg} / \mathrm{d}), \text { STW3 } \\
(612 \mathrm{mg} / \mathrm{d}), \text { LoHyp-57 }(800 \mathrm{mg} / \mathrm{d}) \text { vs. paroxetine } \\
(20 \mathrm{mg} / \mathrm{d}) \text {, fluoxetine }(20 \mathrm{mg} / \mathrm{d}) \text {, sertraline } \\
(50 \mathrm{mg} / \mathrm{d}), \text { placebo; time variable from } 4 \text { to } 12 \mathrm{wk}\end{array}$ & $\begin{array}{l}\text { Systematic review and meta-analysis } \\
\text { of } 27 \text { controlled clinical trials of pa- } \\
\text { tients with mild to severe depression } \\
(n=1472) \text {; CGI, HAM-A, HAM-D }\end{array}$ & $\begin{array}{l}\text { St. John's wort showed a similar } \\
\text { response and remission rate as } \\
\text { standard treatment, but signifi- } \\
\text { cantly lower discontinuation/drop- } \\
\text { out pooled rate as standard drugs. }\end{array}$ & [97] \\
\hline
\end{tabular}

symptoms related to mood, particularly in individuals with atypical depression according to the Inventory of Depressive Symptomatology Self-Rated, version-30 (IDS-SR30) scale and the Spielberger state-trait Anxiety Inventory (STAI) scale [60]. In addition, a randomized, controlled trial showed similar efficacy between monotherapy with curcumin vs. monotherapy with fluoxetine, and even better results when both treatments were combined. In fact, the decrease in depressive symptoms with the combination treatment reached $78 \%$, compared to $65 \%$ for monotherapy with fluoxetine and $63 \%$ for curcumin, although the differences did not reach statistical significance [61]. A subsequent randomized, double-blind, placebo-controlled study conducted by Lopresti et al. reaffirmed the efficacy of curcumin supplementation in the reduction of depressive symptoms. The study involved patients diagnosed with major depressive disorder as evaluated by IDSSR30. At the end of treatment, increases in both thromboxane $B_{2}$ and substance $P$ were observed in urine, while the placebo group showed lower levels of aldosterone and cortisol. At the plasma level, the increase in leptin and endothelin-1 in the group treated with curcumin was associated with greater reductions in the IDSSR30 score. Although the interpretation of these results is complicated, the authors hypothesize that curcumin may enhance the sensitivity of endothelin-1 or leptin receptors, or affect some other mechanism associated with biomarkers which, in turn, exert antidepressant effects [62].

$\mathrm{Ng}$ et al. reviewed six clinical trials in which curcumin (500 to $1000 \mathrm{mg} / \mathrm{d}$, 5 to $8 \mathrm{wk}$ ) was compared to a placebo. In patients with established depression, the clinical efficacy of curcumin in improving depressive symptoms was noteworthy. Significant anxiolytic effects were also observed in three of the trials, with no adverse effects reported in any of them. However, due to the small number of studies available $(6, n=377)$, it was not possible to establish any evidence of the long-term efficacy and safety of curcumin, although its short-term safety, tolerability, and efficacy in patients with depression were all confirmed [63]. Kanchanatawan et al. conducted a double-blind, randomized, placebo-controlled study in which participants diagnosed with MDD were treated with either high doses of curcumin or a placebo along with their standard medication. The MADRS and the HAM-D scores were evaluated at the beginning of the study and then again, several weeks later. The authors observed a higher activity for curcumin vs. the placebo in improving the MADRS score. They also observed a more pronounced effect in men than in women, but with no significant differences in safety or tolerability between curcumin and the placebo. The authors hypothesized that curcumin modifies the immune-inflammatory and oxidative-nitrosative pathways in treated patients. Because these pathways both play an important role in the pathophysiology of major depression, these results justify the use of curcumin as a monotherapy or as an adjuvant treatment for depression [64].

An important barrier to the clinical efficacy of curcumin is its low bioavailability; therefore, efforts have been devoted to developing formulations with greater bioavailability and systemic tissue distribution. In this context, several authors have tested the 


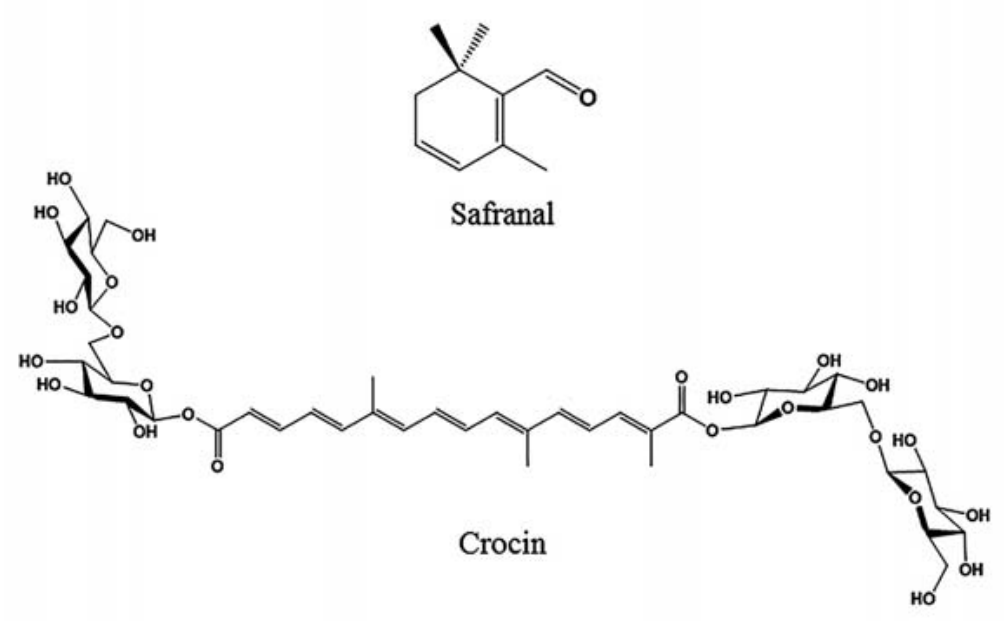<smiles>COc1cc(/C=C/C(=O)CC(=O)/C=C/c2ccc(O)c(OC)c2)ccc1O</smiles><smiles></smiles>

Hypericin

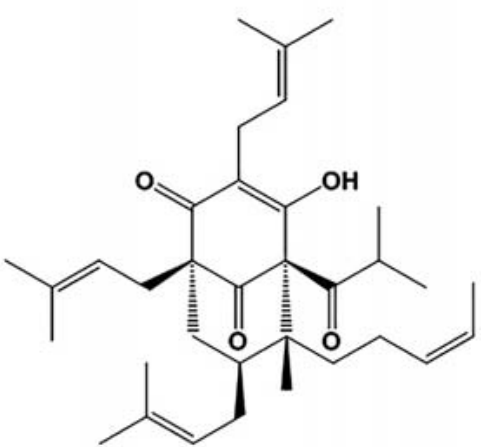

Hyperforin

- Fig. 1 Chemical structures of the active component of saffron (safranal and crocin), turmeric (curcumin), and St. John's wort (hypericin and hyperforin)

effects of formulations elaborated to improve the bioavailability of curcumin. For example, in an open-label study with a combination of curcumin and piperine vs. fluoxetine therapy alone, the authors found significant reductions in anxiety and depression scores of the Hospital Anxiety and Depression Scale (HADS) in patients treated with curcumin/piperine as opposed to standard antidepressants [65]. A meta-analysis of six clinical trials supported the use of curcumin, since it was shown to reduce the symptoms in patients with major depression, both in new formulations (for example, BCM-95 CG) and in the conventional curcumin-piperine formula, with no significant differences in efficacy observed between the two [66]. Another therapeutic combination that could be of interest in the treatment of depression is that of curcumin and saffron. To establish the potential efficacy of this combination, Lopresti and Drummond conducted a randomized, double-blind, placebo-controlled study with MDD patients $(n=123)$, who received either curcumin at low and high doses or curcumin plus saffron. The effects were evaluated by examining the scores from the IDS-SR30 for depression and the STAI for anxiety. The results showed significantly greater improvements in depressive and anxiety-state symptoms in the treatment groups compared to the placebo group, with a higher efficacy in patients with atypical depression compared to the rest of the patients ( 65 vs. $35 \%$, respectively), but the improvements could not be conclusively attributed to either the curcumin dose or the potentiation of its effects with saffron [67]. It is thus likely that curcumin's potential as a therapeutic agent does not depend solely on its bioavailability, but that its therapeutic benefits may be positively influenced by the gut microbiota [68]. In any case, with the experimental and clinical data available and the small number of 
existing trials, it should only be considered as a coadjuvant therapy in conjunction with standard medication [69]. The data of all the protocols are summarized in $>$ Table 3.

With respect to the potential mechanism by which curcumin exerts its effect on depression, different studies have examined various pathways of actuation. For example, the anti-inflammatory properties and antioxidant effects of curcumin may, in part, be responsible for its antidepressant effects, leading it to act through different mechanisms than those employed by standard therapeutic drugs [70,71]. This hypothesis has led to the development of different inflammatory models of depression, in which symptoms and general behaviors associated with the disease are analyzed and compared, including the particular symptoms of depression such as anorexia, sleep disturbances, reduced locomotor activity, anhedonia, and cognitive disturbances [72,73]. The question remains, however, as to whether depression is a manifestation or a consequence of disease. It is clear that there are similarities, as previously discussed, between the general behavior of a given disease and the specific behavior of depressive disorders. In this case, there is a transition to the sensitization of the immuneinflammatory pathways, progressive damage to lipids, proteins, and DNA by oxidative and nitrosative stress, and altered autoimmune responses [74]. In preliminary studies, researchers looked for different proinflammatory markers in patients with depression to establish potential targets for possible treatments [14, 75]. In this context, Dowlati et al. [56] concluded that there is a relationship between two of the proinflammatory cytokines, IL-6 and TNF- $\alpha$, and major depression [57]; however, other cytokines such as IL-1 $\beta$, IL-2, IL-4, IL-10, and interferon- $\gamma$ were not found to have any relevant implications. Lopresti's review [57] concluded that the administration of cognitive behavioral therapy reduces both the depressive symptoms and the proinflammatory cytokines cited as relevant (IL-6 and TNF- $\alpha$ ), although other mediators and factors also experienced modifications, such as reductions in signaling of the TLR4, C-reactive protein, IL-1 antagonist receptor, and IL-5, along with the stimulation of GCSF. In conclusion, these reviews noted a relationship between TNF- $\alpha$ and IL- 6 and major depression, as both cytokines are increased and involved in the response of the acute phase of the disease. However, although changes in these cytokines are clearly significant, it has not yet been possible to establish whether they are the cause or consequence of the disease $[56,57,76]$. Similar results were obtained by Hannestad et al. in a meta-analysis. After analyzing the subgroups stratified by class of antidepressants used, the authors observed that inhibitors of 5-HT reuptake can reduce levels of IL-6 and TNF- $\alpha$, while other effective antidepressants do not [77]. Other groups of mediators involved in inflammation and depression are chemokines, especially MCP-1 (also known as CCL2) and IL-8 (called CXCL8) [78].

Recognizing the potential of curcumin in the treatment of diseases in which oxidative stress and inflammation are involved, several authors hypothesized that its antioxidant and anti-inflammatory properties may be partly responsible for its pharmacological effects, including in the treatment of depression $[64,79]$. In order to establish the relationship between depression and inflammation and to justify the use of curcumin as a potential antidepressant agent because of its anti-inflammatory, monoaminer- gic (mainly 5-HT, but also DA and NA), antioxidant, and immunomodulatory properties, Lopresti et al. reviewed the articles published in the past decade on this subject. They concluded that although more clinical trials are needed, the promising results observed for cyclooxygenase-2 inhibitors against depression support the potential of both the turmeric rhizome and, particularly, curcumin as potential antidepressant agents [25]. More recently, Yu et al. observed that chronic curcumin supplementation in 108 adult men diagnosed with major depression reduced HDRS-17 and MADRS scores, decreased the concentrations of proinflammatory cytokines IL-1 $\beta$ and TNF- $\alpha$, decreased salivary cortisol levels, and increased plasma levels of BDNF in depressed patients vs. the placebo group (see $>$ Table 3 for experimental data) [18].

Of the proinflammatory mediators involved in depression, TNF- $\alpha$ is key; its reduction could thus be one of the main objectives in the fight against this disease. In the case of curcumin, its inhibitory effect on proinflammatory cytokines was evaluated through a meta-analysis of randomized controlled trials. In eight of them, a significant reduction of the circulating concentrations of TNF- $\alpha$ was observed after the administration of curcumin, with an analysis of the results confirming the effect of curcumin in the reduction of plasma concentrations of this cytokine [19]. In the case of the second relevant cytokine, IL-6, Derosa et al. performed a meta-analysis of nine randomized controlled trials to evaluate the efficacy of curcuminoids on plasma concentrations of this protein. In all trials evaluated, a significant reduction of IL-6 was observed after administration of curcuminoids, with the reduction more evident in patients with a high degree of systemic inflammation [80].

In conclusion, after analysis of the studies and reviews carried out, it can be established that depending on the type of depression (acute or chronic), monitoring times, and doses used, curcumin has a positive effect on the reduction of depressive symptoms, with its possible mechanism of action implicating various pathways, mainly antioxidant, anti-inflammatory, and neuroprotective effects. Regarding the relationship between depression and inflammation, curcumin's effect on the reduction of some proinflammatory cytokines, such as TNF- $\alpha[18]$ and IL-6 [76, 80], along with the increase in BDNF and the decrease in cortisol concentrations $[18,19]$ the compound seems to cause are all worth noting, although other pathways and mediators are also involved, such as the aforementioned modulation of endothelin- 1 and leptin $[62,81]$. - Fig. 2 summarizes the main pathways and mediators affected by curcumin related to its antidepressant effects. [82].

\section{Ginkgo biloba L. (Ginkgoaceae)}

The use of ginkgo for medicinal purposes dates back to ancient cultures, principally that of China. It is probably the oldest living tree species and has an extremely long lifespan [83]. The extract of the leaves has been used for various circulatory alterations, facilitating blood flow, and influencing NO systems. It also has a relaxant effect on smooth muscle tissue [84]. In addition, it is used to combat symptoms associated with mild to moderate dementia and in combination therapy with antidepressants [83]. Various clinical trials have focused on the study of ginkgo and its effects on depression. Several previous reports indicated that gingko 


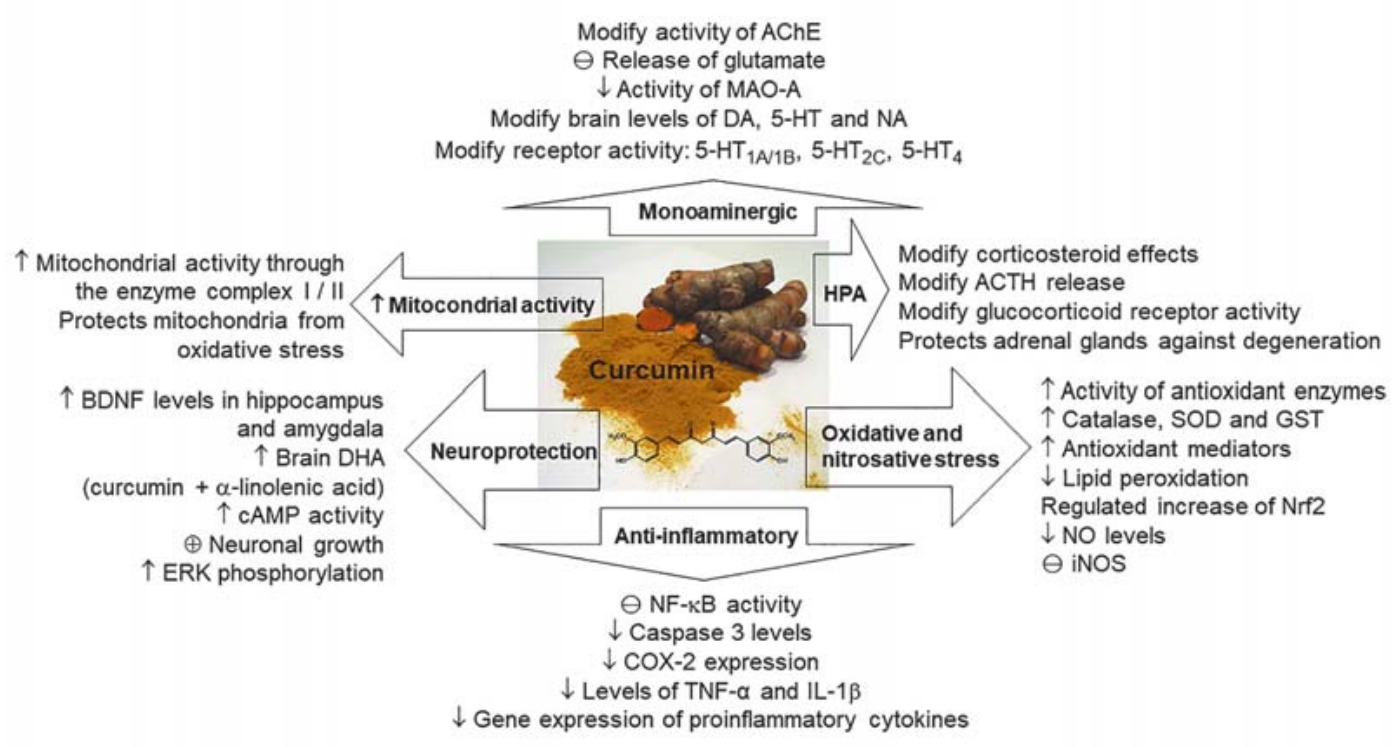

- Fig. 2 Curcumin activity and its possible relationship with antidepressant activity. AChE, acetylcholinesterase; ACTH adrenocorticotropic hormone, cAMP, 3',5'-cyclic adenosine monophosphate; COX-2, cyclooxygenase-2; DA, dopamine; DHA, docosahexaenoic acid; ERK, extracellular signal-regulated kinase; Glu, glutamate; GSH, glutathion; GST, glutathione S-transferase; HPA, hypothalamic-pituitary-adrenal; 5-HT, serotonin; iNOS, inducible nitric oxide synthase; MAO-A, monoamino oxidase-A; NA, noradrenaline; NF-kB, nuclear factor-kB; NO, nitric oxide; Nrf2, nuclear factor erythroid 2-like 2; SOD, superoxide dismutase; $\downarrow$ decreases; $\ominus$ inhibits; $\uparrow$ increases; $\oplus$ stimulates

improved symptoms such as depressed mood; however, these studies had many limitations [85]. Ashton et al. studied its effect on antidepressant-induced sexual dysfunctions, but observed no relevant responses, as only $14 \%$ of subjects exhibited partial improvement in their sexual functioning [86]. In contrast, previous studies had declared that ginkgo leaf was $84 \%$ effective in treating antidepressant-induced sexual dysfunction caused by SSRIs but was more effective in women than men [87]. A similar study was developed by Kang et al., who administered gingko for a period of 2 months to patients with antidepressant-induced sexual dysfunction. The authors observed no significant differences in eight of the outcome items included in the study. Only the item of satisfaction with orgasm exhibited any change at 8 weeks, and in this case, it was the control group that showed a significant improvement [88]. In another trial ( $240 \mathrm{mg} / \mathrm{d}, \mathrm{n}=24,12 \mathrm{wk})$, there were some spectacular individual responses with complete or virtually complete relief of symptoms, but these also occurred in the placebo group [89].

Meston et al. studied the long-term effects of ginkgo on sexual functions in sexually dysfunctional women ( $n=68,8 w k)$ using ginkgo $(300 \mathrm{mg} / \mathrm{d})$, sex therapy focused on training women to attend to genital sensations, and sex therapy plus ginkgo, along with a placebo group. Only when combined with sex therapy did ginkgo increase sexual desire and contentment above the levels of the placebo group; this effect was not extant in the group taking ginkgo alone. Sex therapy alone also significantly enhanced orgasm function versus a placebo [84]. In other work, Hemmeter et al. designed an open, non-randomized pilot study with ginkgo extract on cognitive performance and sleep regulation in de- pressed inpatients $(n=16)$ treated with trimipramine $(200 \mathrm{mg})$ for 6 weeks. Half of the patients received ginkgo $(240 \mathrm{mg} / \mathrm{d})$ for 4 weeks after a baseline week, and the other 8 patients remained on trimipramine monotherapy $(200 \mathrm{mg})$ throughout the entire study. Results showed that ginkgo improved sleep patterns, increasing sleep efficiency and reducing awakenings. Moreover, sleep stage 1 and REM density were reduced, while stage 2 increased [90].

\section{Hypericum perforatum L. (Hypericaceae)}

Several placebo-controlled trials have suggested that St. John's wort extracts have minimal beneficial effects while other trials have found that St. John's wort has beneficial effects similar to those of standard antidepressants. To establish a more conclusive opinion on this subject, Linde and Mulrow reviewed a total of 27 trials that included 2291 patients and established that extracts of St. John's wort are more effective than a placebo for the shortterm treatment of mild to moderately severe depressive disorders [91]. They then reviewed 37 trials (26 compared to a placebo and 14 compared with standard antidepressants, $n=1754$ ) and observed that trials comparing St. John's wort extracts and standard antidepressants were statistically homogeneous [92]. In a third review, they analyzed the effects of St. John's wort extracts on MDD and found that the effects of the extracts tested in these 18 combined studies were higher than those of a placebo in patients with major depression, with results similar to those of standard antidepressants (SSRIs), but with fewer side effects [93]. Another meta-analysis conducted by Rahimi et al. [94] also revealed a significant efficacy and tolerability of St. John's wort in 
MDD (13 controlled clinical trials), comparable to that of SSRIs and better than that of a placebo. Other studies established that in the treatment of moderate to severe major depression, St. John's wort extract WS5570 (900-1800 mg/d) is at least as effective as paroxetine $(20-40 \mathrm{mg} / \mathrm{d})$ and is better tolerated [95], while the $\mathrm{LI}-160$ extract $(900 \mathrm{mg} / \mathrm{d})$ is more effective than fluoxetine $(20 \mathrm{mg} / \mathrm{d})$ and tended toward a better result than that of a placebo [96]. $\mathrm{Ng}$ et al. evaluated 27 clinical trials with 3808 patients (from 1999 to 2014), comparing the use of St. John's wort and SSRIs. In patients with mild to moderate depression, the efficacy and safety of St. John's wort was comparable to SSRI treatments. The limitations of these studies included the disparate number of patients in each ( $\mathrm{n}=30$ to 428 ), the variety of extracts used (calmigen, LI-160, SJW, LoHyp-57), the various duration periods (4 to $12 \mathrm{wk}$ ), the diverse dosages used (20 to $1800 \mathrm{mg} / \mathrm{d}$ ), and the exclusion of patients with severe depression [97].

In 2014, Russo et al. reviewed the pharmacokinetics, mechanisms of action, tolerability, and clinical drug-drug interactions of $H$. perforatum and established some interesting points for consideration in future research [98]. For example, hyperforin, hypericin, pseudohypericin, and flavonoids are the principal components of $H$. perforatum extracts and are considered to be responsible for the extracts' pharmacological effects $[20,98]$. In fact, these authors specifically cite hyperforin and rutin as the main active ingredients in St. John's wort that reduce depressive symptoms; however, other authors also described melatonin as a principal component in this species [99]. As frequently occurs in phytotherapy, the synergy between constituents is a vital aspect of efficacy, as evidenced by the fact that the absence of rutin, a common flavonoid, reduces the antidepressant activity [20] while low hyperforin content preparations are effective in the treatment of depression [98]. Because the pharmacokinetics of these compounds are quite variable, the use of these extracts can induce many drug interactions due to the induction of various cytochrome $\mathrm{P}_{450}$ isozymes and/or P-glycoprotein [98]. However, low-dose hyperforin preparations $(<4 \mathrm{mg}$ ) did not affect P-glycoprotein expression, which could be of interest because the efficacy was the same [20]. Is interesting to note that St. John's wort can also be used to treat certain forms of anxiety [98]. In 2019, Zirak et al. reviewed $H$. perforatum and compiled 29 clinical trials on its antidepressant properties [100]. All the experimental data and protocols of these clinical trials are summarized in $>$ Table 4.

In the reviews of Sarris et al. and Zirak et al., the authors reference different doses, periods of study duration, numbers of patients, and types of trials. For example, dosages varied between 270 and $1800 \mathrm{mg} /$ day of extract, generally of standardized samples (WS5570, PM23, STW 3-VI, ZE117, LI160). Duration periods ranged from 6 weeks to 1 year and the number of patients went from $n=26$ to 426 . The protocols ranged from preliminary and open trials to randomized, double blind, placebo-controlled trials, in some cases, with reference drugs (imipramine, fluoxetine, sertraline, or citalopram). The trials demonstrated that patients with MDD showed only minor improvements compared to the placebo group, whereas trials not restricted to patients with MDD showed greater differences [32]. In addition, the extracts exerted similar effects to those of standard antidepressants when they were compared. In general, then, it seems that standardized extracts of
St. John's wort could be an alternative to standard antidepressants. Moreover, there were fewer numbers of adverse events associated with the use of $H$. perforatum [100].

\section{Piper methysticum G.Forst. (Piperaceae)}

It is commonly known as kava or kava-kava and is used and recognized as an effective agent in treating generalized anxiety disorder with similar efficacy to buspirone or opipramol [101]. In addition to its antianxiety properties, some authors have analyzed the effect of kava in other conditions. Thus, Witte et al. evaluated an acetonic kava extract (WS1490) used in a meta-analysis based on six placebo-controlled, randomized trials that used changes in HAMA during treatment as endpoints. The authors concluded that WS1490 extract, and possibly other kava extracts, are effective and could serve as alternatives to benzodiazepines, SSRIs, and other antidepressants in the treatment of nonpsychotic anxiety disorders [102]. However, kava has been withdrawn from the market in Europe and Canada due to several described hepatotoxic reactions, while the WHO recently recommended using only aqueous extracts [98]. In this context, Sarris et al. carried out a 3-week placebo-controlled, double-blind, crossover trial with 60 adult participants with 4 weeks or more of elevated generalized anxiety (Kava Anxiety Depression Spectrum Study, KADSS) using tablets containing an aqueous extract ( $250 \mathrm{mg}$ of kavalactones/d). The results demonstrated a high reduction in MADRS scores in addition to observed anxiolytic effects, leading the authors to conclude that the aqueous kava preparation has significant antidepressant activity and is equally effective in cases where anxiety is accompanied by depression. Moreover, the aqueous extract was found to be safe, with no serious adverse effects and no clinical hepatotoxicity [101].

\section{Sedum roseum (L.) Scop. (syn: Rhodiola rosea L., Crassulaceae)}

Golden root, also known as roseroot, has been studied in humans, with several previous trials demonstrating that the standardized dried rhizome extract (Rhodiola SHR-5) significantly improves depressive symptoms vs. a placebo. The first study of interest was performed by Darbinyan et al., who studied the efficacy and safety of the standardized extract SHR-5 obtained from the rhizomes of the plant in patients suffering from an episode of mild/ moderate depression. The clinical trial (phase III) was a randomized, double-blind, parallel, placebo-controlled study, with patients (both sexes, 18 to 70 years old, treatment duration: $6 \mathrm{wk}$ ) selected according to DSM-IV diagnostic criteria for depression, the severity of which was determined by BDI and HAM-D questionnaires. Three groups of patients received $340 \mathrm{mg} / \mathrm{d},(\mathrm{n}=31)$, $680 \mathrm{mg} / \mathrm{d}(\mathrm{n}=29)$, or a placebo $(n=29)$. The efficacy of the extract was assessed with total and specific subgroup HAM-D scores. The authors concluded that the standardized extract SHR-5 has antidepressant effects in patients with mild to moderate depression at both 340 and $680 \mathrm{mg} /$ day [103]. The extract also improved HAM-D scores in both the $340 \mathrm{mg}$ (35\%) and $680 \mathrm{mg}(30 \%)$ groups compared to baseline, but not in the placebo group (3\%); there were no serious adverse side effects in any group [104]. To confirm these properties, different authors investigated golden root's application in humans in several clinical 
trials, some of them of good quality. Mao et al. carried out various clinical trials to ascertain the efficacy of this species in cases of depression. In 2015, they developed a phase II, randomized, placebo-controlled clinical trial $(n=57)$ over a 12 -week period. Patients received the standardized extract, sertraline, or a placebo and the data were analyzed using HAM-D, BDI, and Clinical Global Impression Change (CGI/C) scores. Although the extract had a lower antidepressant effect than the positive control (sertraline), it exerted a positive effect in individuals with mild to moderate depression and led to fewer adverse reactions [105]. Previously, these same authors had studied the effects of golden root on MDD using a 12-week, randomized, double blind, placebo-controlled, parallel group study design. Patients diagnosed with MDD received the extract $(340-1360 \mathrm{mg} / \mathrm{d})$, sertraline (50$200 \mathrm{mg} / \mathrm{d}$ ), or a placebo. The primary outcome measure was change over time in the mean 17-item HAM-D score. The results for golden root extract compared to conventional antidepressant therapy for MDD established that there were no significant differences between the two treatments, with the effects of golden root being similar to those of sertraline [106]. Amsterdam and Panossian compiled the clinical trial results for golden root extracts in patients with depressive syndromes. Their review included two randomized, double-blind, placebo-controlled trials with MDD patients $(n=146)$ and seven open-label studies with patients diagnosed with mild depression $(n=714)$. The compilation demonstrated the antidepressant effect of the extracts, which were well tolerated and had a favorable safety profile. The authors established that the possible beneficial effects on mood were most likely due to modifications to the neurotransmitter receptor, molecular networks, and neuroendocrine system implicated in this process [107].

\section{Other common species studied for their antidepressant effects}

The number of clinical trials with other antidepressant species is quite limited. For example, only a few studies on humans have been carried out with lavender (Lavandula angustifolia Mill., syn: Lavandula officinalis Chaix, Lamiaceae) or its essential oil. Of these, Akhondzadeh et al. compared the efficacy of a lavender tincture with that of imipramine in the treatment of mild to moderate depression, as well as the possible adjuvant effect of this tincture in a 4-week, double-blind, randomized trial. Only the combination of imipramine and lavender tincture was more effective than imipramine alone. The authors thus concluded that this combination could be of interest in the management of mild to moderate depression [108]. However, in a more recent study, the depression indices in lavender ( $1.5 \mathrm{~g}$ tea bag placed in a cup of boiling water for 10-15 min and then taken with candy every $12 \mathrm{~h}$ ) and placebo groups showed no significant differences in decreased depression scores, whereas the reference group (venlafaxine, $37.5 \mathrm{mg}$ ) showed decreases after 6 weeks of treatment [109]. These results indicated that the use of an extract could be more favorable than a tisane.

No relevant clinical assays have been performed with lemon balm (Melissa officinalis L., Lamiaceae) with regard to depression. Of the studies conducted on this plant for the treatment of other maladies, Haybar et al.'s double-blind placebo-controlled, clinical trial is noteworthy. The study was performed with 80 patients diagnosed with chronic stable angina, who were divided randomly into two groups (lemon balm $3 \mathrm{~g} / \mathrm{d}$ for 8 wk as a supplement or a placebo). At the end of the experiment, the test group ( $M$. officinalis) exhibited a significant reduction in scores for depression, anxiety, stress, and total sleep disturbance compared to the placebo group, as measured with the Depression, Anxiety and Stress Scale (DASS-21) and PSQI tests. The authors concluded that M. officinalis could decrease depression, anxiety, stress, and sleep disorders in patients with chronic stable angina [110].

In the case of ginseng (Panax ginseng C. A.Mey., Araliaceae), a relevant study was published in which 35 female outpatients (18 to 65 years old) with major depression and residual symptoms received Korean red ginseng $(3 \mathrm{~g} / \mathrm{d}, 8 \mathrm{wk})$ and were then evaluated for depressive symptoms by means of the Depression Residual Symptom Scale (DRSS) and MADRS. The general severity of symptoms was assessed using the CGIS while the Depression and Somatic Symptom Scale (DSSS) was used for the evaluation of somatic symptoms. After 8 weeks of treatment, patients exhibited a significant decrease in depressive symptoms on the DRSS and MADRS scales, with improved CGI-S scores with regard to the severity of illness. The somatic symptoms on the DSSS were also attenuated during the assay. The authors concluded that Korean red ginseng could be of interest as an adjuvant treatment for patients with residual symptoms of major depression, but further placebo-controlled assays are necessary for confirming these results [111].

The number of clinical trials with valerian (Valeriana officinalis L., Caprifoliaceae) is limited in the case of depression, with some using the standardized sleep and psychometric tests to evaluate the clinical efficacy of valerian and its consequences. In a doubleblind, placebo-controlled, crossover clinical trial, no statistical differences were observed between groups receiving different doses of valerian (400 and $600 \mathrm{mg}$ ) and the placebo group, probably due to the low number of participants ( $n=16,5$ males and $11 \mathrm{fe}$ males) [112].

KeenMind CDRI08 is a standardized extract from brahmi [Bacopa monnieri (L.) Wettst., Plantaginaceae], which is supposed to improve cognitive function in healthy human subjects, particularly in the elderly [113-115]. Indeed, the extract $(2 \times 150 \mathrm{mg}$, $\mathrm{n}=23$ ) was studied in a double-blind, placebo-controlled, randomized trial conducted over a 12-week period. In this assay, brahmi significantly improved the speed of visual information processing, learning rate, memory consolidation, and state of anxiety versus the placebo, with maximal effects at 12 weeks $[113,114]$. In another clinical trial, 107 healthy participants were studied in a double-blind, placebo-controlled experiment; 62 subjects completed the study. Neuropsychological testing was conducted at baseline and after 90 days of treatment using the Cognitive Drug Research battery, a cognitive assessment system. Brahmi extract $(2 \times 150 \mathrm{mg})$ significantly improved the performance factor of working memory, more than it affected the spatial working memory accuracy. This clinical trial supported the cognitive enhancing effects in healthy humans of brahmi extract described in other studies [115].

As commented above, several studies have established the relationship between a higher consumption of green tea and a lower 
prevalence of depression [38]. Niu et al. designed a cross-sectional study carried out on 1058 community-dwelling elderly Japanese individuals ( $\geq 70$ years) and concluded that frequent consumption of green tea is associated with a lower prevalence of depressive symptoms in this community, as measured with the Geriatric Depression Scale (GDS) [116]. As a revision of the potential of green tea, Rothenberg and Zhang reviewed the relationship between green tea consumption and its biochemical and neurobiological effects. They found that multiple pathways seem to be affected by various constituents in green tea, which can collectively lead to antidepressant effects in tea drinkers; there is also a clear relationship with its anti-inflammatory effects. For example, the teamediated antidepressant activity involves the reduction of inflammation, the improvement of monoaminergic systems, and the reduction of the stress response via normalized HPA axis activity. In addition, the ERK/CREB/BDNF signaling pathway is upregulated by various compounds found in tea, such as teasaponin, L-theanine, epigallocatechin gallate, epicatechin, and their combinations with their metabolites. Other mechanisms include increased short-chain fatty acids/AMPK signaling by oxidized tea polyphenols, which improve the generation of monoamines and BDNF upregulation of the gut microbiota, especially Lactobacillus and Bifidobacterium. The authors concluded that there are simply not enough data to specify which mechanisms are responsible for producing the largest net induction of antidepressant response and thus propose this topic for future research on depression [117].

The dried flowers of Echium amoenum Fisch. \& C. A.Mey. (Boraginaceae), commonly known as red feathers, are used in Iran for nervous disorders. Sayyah et al. studied the efficacy of an aqueous extract in patients with mild to moderate MDD as measured with the DSM-IV criteria and using the HAM-D 17 scale. In a doubleblind, parallel-group, randomized trial, the treatment group (500 mg/day, $n=19$ ) was compared with a placebo group ( $n=16$ ) during a 6 -week period. At 4 and 6 weeks, the extract showed higher activity than the placebo, but with no differences in adverse events. The results showed a greater effect for the extract than for the placebo in reducing depressive symptoms on the HAM-D after 4 weeks, but this effect disappeared 2 weeks later [118]. Several limited investigations with Apocynum venetum L. (Apocynaceae) have also been carried out in humans, but only Yamatsu et al.'s study analyzed the effect of GABA $(100 \mathrm{mg})$ and A. venetum leaf extract $(50 \mathrm{mg})$ on sleep improvement. Oral administration of both substances had beneficial effects on sleep, shortening sleep latency by $4.3 \mathrm{~min}$ and increasing non-REM sleep time by $5.1 \%$ [119]. Firoozabadi et al. performed a randomized, triple-blind, controlled clinical trial on patients with MDD using Cuscuta planiflora Ten. (Convolvulaceae) $(500 \mathrm{mg})$, Nepeta menthoides Boiss. \& Buhse (Lamiaceae) $(400 \mathrm{mg})$, and a combination of a tricyclic antidepressant and a selective serotonin receptor inhibitor (no drug names were provided). Patients ( $n=43$ ) were randomly divided into three groups; two received the extract plus the reference drugs and the third group received only the drugs. Depression was measured before and after 8 weeks with the aid of the BDI and the Hamilton Depression Inventory (HDI). After treatment, there was a significant decrease in mean scores for both the $\mathrm{BDI}$ and the $\mathrm{HDI}$ in all three groups. Moreover, the decrease in scores was greater in the groups treated with both plants and drugs compared to the group receiving drugs alone [120]. There are various clinical studies on gotu kola (C. asiatica) in the literature, but most of them deal with dermatological disorders, not neurological troubles. There is only one reference to its anxiolytic properties [39], with one other on cognitive function [40], but no specific assays on depression have been performed. With respect to the possible use of Cannabis sativa L. (Cannabaceae) as an antidepressant agent, Black et al. carried out a systematic review and meta-analysis with 42 eligible studies for depression; 23 of them were randomized controlled trials $(n=2551)$. The authors established that, "There is scarce evidence to suggest that cannabinoids improve depressive disorders and symptoms" [121]. Nevertheless, Ferber et al. have proposed studying the potential therapeutic value of cannabidiol, with or without additional tetrahydrocannabinol, after the addition of terpenes (mircene, limonene, and others from essential oils) to treat patients with depression [122].

\section{Studies with combinations of plants}

Bangratz et al. performed an observational study ( $n=45$ adults, 18 to $85 \mathrm{yr}$ old) suffering from mild to moderate depression (International Statistical Classification of Diseases and Related Health Problems 10th Revision Definition) who reached a score of 8-18 on the HDRS. Patients received dietary supplements that contained a combination of golden root $(154 \mathrm{mg})$ and saffron $(15 \mathrm{mg}$ ) extracts ( 2 tablets/d for $6 \mathrm{wk}$ ). At the end of the study, HDRS scores decreased significantly by $58 \%$, with improved scores in $85 \%$ of patients. A significant drop in both HADS scores was also observed. The authors concluded that the combination of golden root and saffron could be useful for the management of mild to moderate depression and improve symptoms of both depression and anxiety; however, they recommended conducting a double-blind, placebo-controlled study to confirm their hypothesis [123]. The combination of St. John's wort with low- or highdose valerian extract to treat anxious depression was more effective with the higher dose of valerian, but the effect was not significant [124]. However, administration of a combination of St. John's wort $(1.8 \mathrm{~g} / \mathrm{d} \times 3$; equivalent to $990 \mathrm{mg} \times 3$ of hypericin) and kava $(2.66 \mathrm{~g} \times 3 / \mathrm{d}$; equivalent to $50 \mathrm{mg} \times 3$ of kavalactones) for 2 weeks produced a significantly greater reduction in self-reported depression on the BDI-II over a placebo in the first controlled phase. Unfortunately, in the crossover phase, a replication of those effects in the delayed medication group did not occur [125].

\section{Concluding Remarks}

Among the approximately 155 species reviewed [9], just a reduced number have been subjected to clinical trials and only 5 of those (turmeric, saffron, St. John's wort, ginkgo, and golden root) can be considered relevant. Indeed, solely one principle (curcumin from turmeric) can be considered of high interest as it has been studied extensively. After previous preclinical studies of species tested in rodents, a great number of clinical trials were selected for review. In many cases, the roles of 5-HT, NA, and DA were analyzed, as well as the neuroendocrine and neuroprotective effects 


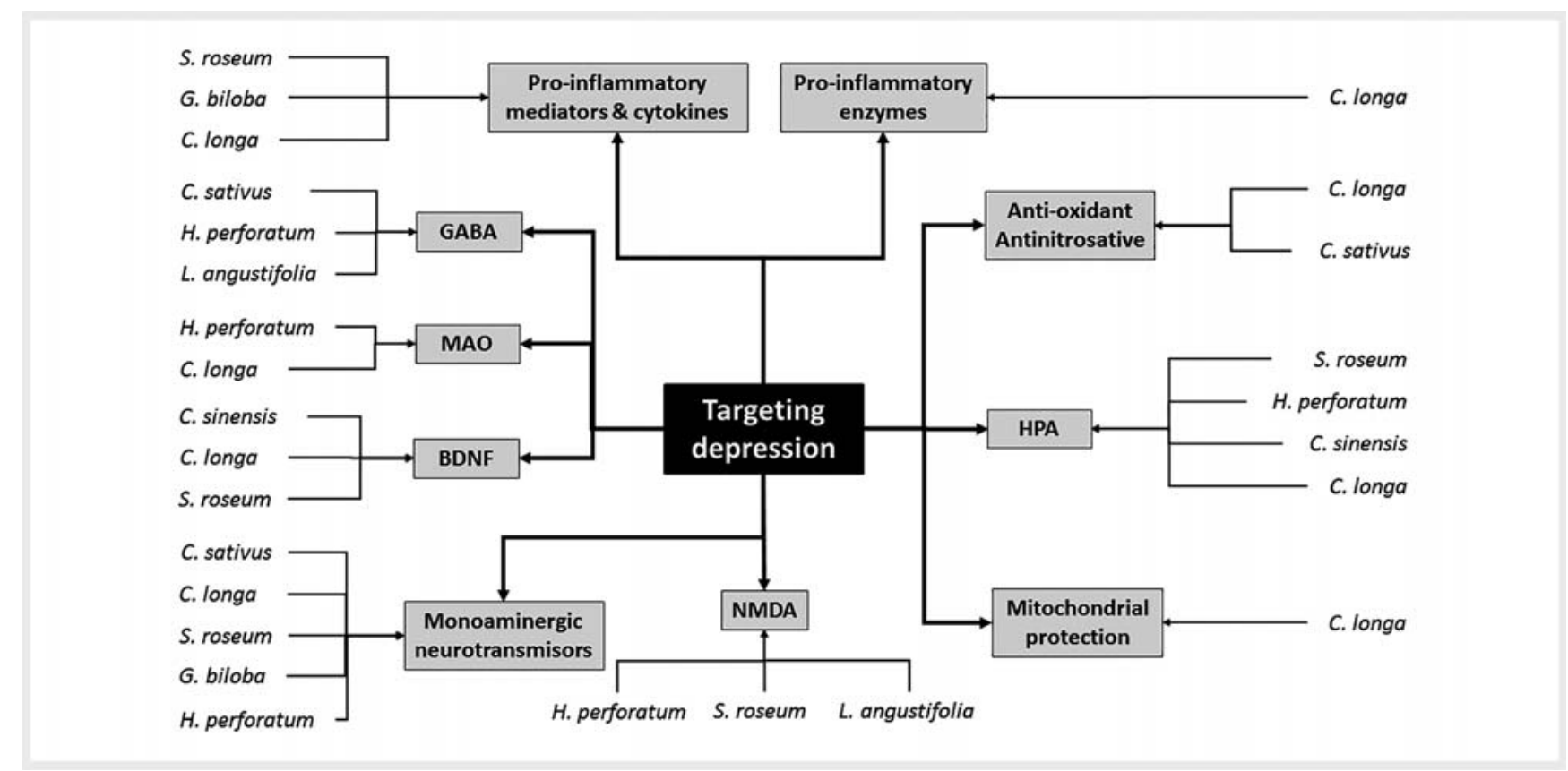

- Fig. 3 Significant processes targeted in the mechanisms used by medicinal plants to alleviate depression. BDNF, brain-derived neurotrophic factor; GABA, $y$-aminobutyric acid; HPA, hypothalamic-pituitary-adrenal; MAO, monoamine oxidase; NMDA, N-methyl-D-aspartic acid. C. sinensis, Camellia sinensis; C. sativus, Crocus sativus; C. longa, Curcuma longa; G. biloba, Ginkgo biloba; H. perforatum, Hypericum perforatum; L. angustifolia; Lavandula angustifolia; S. roseum, Sedum roseum.

of natural products and the plant extracts. In general, the protocols employed varied, but some were used repeatedly, such as the HAM-D or BDI compiled in - Table 1 . With respect to the mechanisms implicated in the antidepressant effects of these plants, they varied depending on the species and kind of extract used. - Fig. 3 summarizes the main neurotransmission and other significant processes targeted in the mechanisms used by medicinal plants to alleviate depression.

For example, the antidepressant mechanism of saffron most likely involves the inhibition of both MAO-A and MAO-B, together with inhibition of the neuronal reuptake of DA, NA, and 5-HT, but the NMDA antagonist and $\mathrm{GABA}_{\mathrm{A}}$ agonist activities of some of its principles may also be partly responsible for its antidepressant properties. Regarding the monoaminergic neurotransmitters (5-HT, DA, and NA), other species have been cited as potential inhibitors, in some cases, through transporters via their metabolism, uptake, or synthesis. Turmeric, golden root, ginkgo, and St. John's wort are the principal species targeting this neurotransmission, although some of them have other complementary mechanisms. Some species can also exert their effects through the HPA axis and the role of corticosteroids through the release of the corresponding hormones (turmeric, golden root, green tea, and St. John's wort). In the case of BDNF, some species seem to prevent the decrease in hippocampal BDNF signaling while promoting neurogenesis, such as Andrographis paniculata (Burm.f.) Nees (Acanthaceae), which could also be considered a valuable antidepressant mechanism [126].

In many cases, antioxidant and anti-inflammatory properties were implicated, as well as proinflammatory mediators such as
IL-2, IL-6, and TNF- $\alpha$. Indeed, some plants, such as turmeric, modify the activity of proinflammatory mediators, reducing IL-6, IL-8, and TNF- $\alpha$, as well as TLR-4, C-reactive protein, IL-1 receptor (antagonist), and the stimulation of GCSF and MCP-1. This is in addition to its antioxidant and anti-nitrosative properties, which improve its antidepressant effects by reducing the inflammatory response. Golden root also reduces the proinflammatory mediators TNF- $\alpha$ and IL- $1 \beta$, and, like ginkgo, has antioxidant and anti-nitrosative effects. Ginkgo is also of interest because it was shown to attenuate several parallel issues in women with sexual problems, along with the general observation that ginkgo can increase sexual desire and reduce sleep stage 1 and REM density while increasing stage 2 . This effect is also mediated by the reduction of proinflammatory mediators (TNF- $\alpha$ and IL-1 $\beta$ ) and the blockage of 5-HT release.

In the case of clinical trials with patients diagnosed with MDD and treated with medicinal plants, the number is small, but the data from them is relevant. For example, studies on the use of saffron for treating MDD showed not only that it could improve symptoms of depression, but also that it was as effective as synthetic antidepressants, implying that saffron is effective for treating MDD without the adverse effects of synthetic drugs [54]. Another relevant plant studied as an antidepressant in humans is St. John's wort. In this case, the clinical trials demonstrated that larger trials restricted to patients with MDD showed only minor effects over placebo, whereas older and smaller trials not restricted to patients with MDD showed marked effects. However, in general, when their activity was compared to that of synthetic antidepressants, standardized extracts of St. John's wort showed 
similar effects to those of standard drugs in the treatment of mild and moderate depression, with a reduced number of adverse events [100], making it a candidate for application in pharmacological treatments. Moreover, its use in clinical practice is common, especially in Germany, where a case-control study focusing on its prescription found that it was associated with a decreased risk of dementia [127], as was escitalopram, in contrast to SSRIs or serotonin noradrenaline reuptake inhibitors, which increased the risk. In addition, the combination of St. John's wort with kava was shown to improve depression compared to a placebo. Nevertheless, it must be noted that synergistic effects of St. John's wort with other pharmacological agents can be potentially life-threatening due to increased serotonin levels. This side effect should be taken into account by both patients and prescribers. Moreover, St. John's wort should not be prescribed, even as a monotherapy, in people with bipolar disorder or schizophrenia since it could actually worsen psychotic symptoms [128].

A third drug of interest for treating MDD is golden root, as it was demonstrated that there are no significant differences between golden root extract and the conventional antidepressant drug sertraline in the treatment of patients with MDD $[105,106]$. In addition, golden root associated with saffron could be useful for the management of mild to moderate depression. Curcumin, from turmeric, was also tested in combination with other antidepressants in patients with MDD and showed significant positive effects in both groups as measured with CGIS, HDRS, and MADRS scales, with faster relief from depressive symptoms than a placebo [59].

The association of different medicinal plants, i.e., polyherbal prescription, seeks to obtain the best results with the fewest non-desirable effects. Curcumin, the principal active compound of turmeric, reduces depressive symptoms in patients with established depression, improving their overall condition. However, the principal problem of curcumin is its low bioavailability, which can be improved with piperine or special formulations. Other possible associations can also lead to improvement of symptoms due to a synergistic effect. This occurs with the combination of curcumin and saffron, which improves the symptoms of depression and anxiety when compared to a placebo, as do the combinations of golden root and saffron, along with St. John's wort and valerian or kava.

Other species of interest are B. monnieri, L. angustifolia, M. officinalis, $P$. ginseng, and $V$. officinalis, but the limited clinical studies developed to date hinder the assessment of these medicinal plants as relevant antidepressant drugs at the moment. Still, in some cases, they could be of interest for developing future trials.

It is well known that the long-term use of antidepressant drugs frequently causes side effects that can jeopardize treatment adherence. Moreover, the UK's NICE (National Institute for Health and Clinical Excellence) and the Royal College of Psychiatrists recently acknowledged that withdrawal symptoms related to antidepressants can last for months or even years $[129,130]$. These facts have promoted the search for complementary and alternative treatments, which is attracting intense interest globally, with many researchers working on both herbal and poly-herbal formulations. Several factors contribute to this higher demand, includ- ing the fact that plant-based therapy is generally considered safer than conventional medicine. It also tends to be cost-effective, well tolerated, is often more readily available to all kinds of populations and has been tested for years in folk medicine. This does not mean that medicinal plants should be used without precautions; in fact, quite the opposite is true. As mentioned above, there may be serious issues involved with St. John's wort and serotoninergic increases. These therapies are not risk-free and should only be taken with a prescription and under a physician's supervision. Although it may seem obvious, it should be emphasized that the "absence of evidence" of toxicity is not the same as "evidence of absence" of toxicity. Thus, it is necessary to conduct more research to elucidate the mechanisms of action, the effective dosages, and the interactions with other phytochemical or pharmacological agents to avoid undesirable effects or even life-threatening events, which plant-based therapies may cause. Of course, one of the limitations of our study, despite having focused only on the most relevant and methodologically stronger clinical trials, is that the botanical extracts used in behavioral research are not standardized. Indeed, comparing the results of all of the studies without standardization of the compounds under study may invalidate the validity of the results, even if they are consistent with each other. Even standardization based on concentrations of one or more psychoactive constituents does not guarantee consistency among lots or "phytoequivalence", which is crucial when examining the literature on herbal psychopharmacology or phytotherapy [32].

The epigenetic issue is also an important limitation that has already proven difficult to include in large clinical trials; its introduction in herbal trials is thus harder still. Epigenetic studies show that combinations of compounds not only trigger gene expression but may, in fact, themselves be the triggers. An example of this can be found in a study on a multicomponent herbal product composed of different anti-inflammatory herbs in which the epigenetic assays showed that the gene expression profile of the whole formula was unique and did not solely reflect the effects of the individual herbs [131]. Another study provides evidence that $H$. perforatum not only affects the transcription of many genes but modulates gene expression similar to the way in which a conventional antidepressant does [132]. Thus, future proteomic studies of other herbal psychotropics may reveal gene expressions similar to those of conventional pharmacotherapies. The "omics" genetic technologies, which include pharmacogenomics, proteomics (epigenetics), and metabolomics, are therefore essential for the clinical validation of herbal medicines [32]; unfortunately, this information is not always available.

Notwithstanding these limitations, our aim in this review is to provide a summary of the available data regarding the important questions raised in order to facilitate the work of practitioners and prescribers. At the same time, we provide a picture focusing on the main objectives in alleviating depression with medicinal plants and their active principles. There are at least 670 reports of antidepressant plants in PubMed, 155 of which were already compiled in the first part of this work, which dealt with the preclinical trials [9]. This second part only addresses clinical trials. PubMed yields a total of 121 such trials; of those, the present paper examined 18, but only 6 are actually relevant studies. Still, from these studies, it 
becomes more evident which conditions an herbal remedy should meet in order to be an effective antidepressant. They should have anti-inflammatory and antioxidant properties as well as the ability to mediate proinflammatory factors, mitochondrial damage, and oxidative stress in neuronal damage. Although inflammatory processes interact with the immune system through biochemical and biobehavioral mechanisms that have not yet been fully elucidated, it seems clear that depression can be considered a psychoneuroimmunological disorder.

In conclusion, after conducting this review, we can say that saffron, turmeric (or its principle, curcumin), and St. John's wort are currently the principal species of interest for potential use as antidepressant agents, with tested effects against both a placebo and standard treatments, whereas the remaining plants require larger clinical trials in order to be considered appropriate alternative treatments to combat the challenge of depression worldwide.

\section{Contributors' Statement}

The article has been thought, designed and written by the two authors

\section{Acknowledgements}

The authors would like to thank Laura Gatzkiewicz for her contribution in the process of improving the language of the text.

\section{Conflict of Interest}

The authors declare that they have no conflict of interest.

\section{References}

[1] American Psychiatric Association. Diagnostic and statistical Manual for mental Disorders, $5^{\text {a }}$ ed (DSM-5). Arlington: American Psychiatric Publishing; 2013

[2] Krishnan V, Nestler EJ. The molecular neurobiology of depression. Nature 2008; 455: 894-902

[3] World Health Organization. Depression and other common mental Disorders. Global Health Estimates. Geneve: WHO; 2017

[4] Lim GY, Tam WW, Lu Y, Ho CS, Zhang MW, Ho RC. Prevalence of depression in the community from 30 countries between 1994 and 2014. Sci Rep 2018; 8: 2861

[5] Saveanu RV, Nemeroff CB. Etiology of depression: genetic and environmental factors. Psychiatr Clin North Am 2012; 35: 51-71

[6] Kaymaz N, van Os J, Loonen AJM, Nolen WA. Evidence that patients with single versus recurrent depressive episodes are differentially sensitive to treatment discontinuation: a meta-analysis of placebo-controlled randomized trials. J Clin Psychiatry 2008; 69: 1423-1436

[7] Carvalho LA, Pariante CM. In vitro modulation of the glucocorticoid receptor by antidepressants. Stress 2008; 11: 411-424

[8] Cepeda MS, Stang P, Makadia R. Depression is associated with high levels of C-reactive protein and low levels of fractional exhaled nitric oxide: results from the 2007-2012 National Health and Nutrition Examination Surveys. J Clin Psychiatry 2016; 77: 1666-1671

[9] Moragrega I, Ríos JL. Medicinal plants in the treatment of depression: evidence from preclinical studies. Planta Med 2021. doi:10.1055/a1338-1011
[10] Dantzer R, O'Connor JC, Freund GG, Johnson RW, Kelley KW. From inflammation to sickness and depression: when the immune system subjugates the brain. Nat Rev Neurosci 2008; 9: 46-56

[11] Miller AH, Raison CL. The role of inflammation in depression: from evolutionary imperative to modern treatment target. Nat Rev Immunol 2016; 16: $22-34$

[12] Jha MK, Trivedi MH. Personalized antidepressant selection and pathway to novel treatments: clinical utility of targeting inflammation. Int J Mol Sci 2018; 19: 233

[13] Setiawan E, Attwells S, Wilson AA, Mizrahi R, Rusjan PM, Miler L, Xu C, Sharma S, Kish S, Houle S, Meyer JH. Association of translocator protein total distribution volume with duration of untreated major depressive disorder: a cross-sectional study. Lancet Psychiatry 2018; 5: 339-347

[14] Zunszain PA, Hepgul N, Pariante CM. Inflammation and depression. Curr Topics Behav Neurosci 2013; 14: 135-151

[15] Christmas DM, Potokar J, Davies SJ. A biological pathway linking inflammation and depression: activation of indoleamine 2,3-dioxygenase. Neuropsychiatr Dis Treat 2011; 7: 431-439

[16] Pariante CM. Why are depressed patients inflamed? A reflection on 20 years of research on depression, glucocorticoid resistance and inflammation. Eur Neuropsychopharmacol 2017; 27: 554-559

[17] Frodl TS, Koutsouleris N, Bottlender R, Born C, Jäger M, Scupin I, Reiser M, Möller HJ, Meisenzahl EM. Depression-related variation in brain morphology over 3 years: effects of stress? Arch Gen Psychiatry 2008; 65: 1156-1165

[18] Yu J], Pei LB, Zhang Y, Wen ZY, Yang JL. Chronic supplementation of curcumin enhances the efficacy of antidepressants in major depressive disorder: a randomized, double-blind, placebo-controlled pilot study. J Clin Psychopharmacol 2015; 35: 406-410

[19] Sahebkar A, Cicero AFG, Simental-Mendía LE, Aggarwal BB, Gupta SC. Curcumin downregulates human tumor necrosis factor- $\alpha$ levels: A systematic review and meta-analysis of randomized controlled trials. Pharmacol Res 2016; 107: 234-242

[20] Sarris J. Herbal medicines in the treatment of psychiatric disorders: 10-year updated review. Phytother Res 2018; 32: 1147-1162

[21] Manji HK, Drevets WC, Charney DS. The cellular neurobiology of depression. Nat Med 2001; 7: 541-547

[22] Maes M, Yirmyia R, Noraberg J, Brene S, Hibbeln J, Perini G, Kubera M, Bob P, Lerer B, Maj M. The inflammatory and neurodegenerative (I\&ND) hypothesis of depression: leads for future research and new drug developments in depression. Metab Brain Dis 2009; 24: 27-53

[23] Raison CL, Miller AH. Is depression an inflammatory disorder? Curr Psychiatry Rep 2011; 13: 467-475

[24] Leonard B, Maes M. Mechanistic explanations how cell-mediated immune activation, inflammation and oxidative and nitrosative stress pathways and their sequels and concomitants play a role in the pathophysiology of unipolar depression. Neurosci Biobehav Rev 2012; 36: 764-785

[25] Lopresti AL, Hood SD, Drummond PD. Multiple antidepressant potential modes of action of curcumin: a review of its anti-inflammatory, monoaminergic, antioxidant, immune-modulating and neuroprotective effects. J Psychopharmacol 2012; 26: 1512-1524

[26] Vadnie CA, McClung CA. Circadian rhythm disturbances in mood disorders: insights into the role of the suprachiasmatic nucleus. Neural Plast 2017; 2017: 1504507

[27] Miller AH, Raison CL. Immune system contributions to the pathophysiology of depression. Focus 2008; 6: 36-45

[28] Coleman JA, Green EM, Gouaux E. X-ray structures and mechanism of the human serotonin transporter. Nature 2016; 532: 334-339

[29] Zhang FH, Wang ZM, Liu YT, Huang JS, Liang S, Wu HH, Xu YT. Bioactivities of serotonin transporter mediate antidepressant effects of Acorus tatarinowii Schott. J Ethnopharmacol 2019; 241: 111967 
[30] Matveychuk D, Thomas RK, Swainson J, Khullar A, MacKay MA, Baker GB, Dursun SM. Ketamine as an antidepressant: overview of its mechanisms of action and potential predictive biomarkers. Ther Adv Psychopharmacol 2020; 10: 2045125320916657

[31] Dhingra D, Sharma A. A review on antidepressant plants. Nat Prod Rad 2006; 5: 144-152

[32] Sarris ], Panossian A, Schweitzer I, Stough C, Scholey A. Herbal medicine for depression, anxiety and insomnia: a review of psychopharmacology and clinical evidence. Eur Neuropsychopharmacol 2011; 21: 841-860

[33] Farahani MS, Bahramsoltani R, Farzaei MH, Abdollahi M, Rahimi R. Plantderived natural medicines for the management of depression: an overview of mechanisms of action. Rev Neurosci 2015; 26: 305-321

[34] Lee $G$, Bae $H$. Therapeutic effects of phytochemicals and medicinal herbs on depression. Biomed Res Int 2017; 2017: 6596241

[35] Bakhshaeil S. Effect of nine medicinal plants as a traditional treatment on depression. J Appl Pharm 2017; 9: 244

[36] Rahman MR, Ali M, Sharif M, Tajmin A. A review study on the traditional plants has potential antidepressant property. MOJ Cell Sci Rep 2017; 4: 00100

[37] Muszyńska B, Łojewski M, Rojowski J, Opoka W, Sułkowska-Ziaja K. Natural products of relevance in the prevention and supportive treatment of depression. Psychiatr Pol 2015; 49: 435-453

[38] Dong X, Yang C, Cao S, Gan Y, Sun H, Gong Y, Yang H, Yin X, Lu Z. Tea consumption and the risk of depression: a meta-analysis of observational studies. Aust N Z J Psychiatry 2015; 49: 334-345

[39] Sarris J, Mclntyre E, Camfield DA. Plant-based medicines for anxiety disorders, part 2: a review of clinical studies with supporting preclinical evidence. CNS Drugs 2013; 27: 301-319

[40] Puttarak P, Dilokthornsakul P, Saokaew S, Dhippayom T, Kongkaew C, Sruamsiri R, Chuthaputti A, Chaiyakunapruk N. Effects of Centella asiatica (L.) Urb. on cognitive function and mood related outcomes: A systematic review and meta-analysis. Sci Rep 2017; 7: 10646

[41] Chusak C, Thilavech T, Henry C], Adisakwattana S. Acute effect of Clitoria ternatea flower beverage on glycemic response and antioxidant capacity in healthy subjects: a randomized crossover trial. BMC Complement Altern Med 2018; 18: 6

[42] Shafiee M, Arekhi S, Omranzadeh A, Sahebkar A. Saffron in the treatment of depression, anxiety and other mental disorders: Current evidence and potential mechanisms of action. J Affect Disord 2018; 227: 330-337

[43] Ulbricht C, Conquer J, Costa D, Hollands W, lannuzzi C, Isaac R, Jordan JK, Ledesma N, Ostroff C, Serrano JM, Shaffer MD, Varghese M. An evidencebased systematic review of saffron (Crocus sativus) by the Natural Standard Research Collaboration. J Diet Suppl 2011; 8: 58-114

[44] Lopresti AL, Drummond PD. Saffron (Crocus sativus) for depression: a systematic review of clinical studies and examination of underlying antidepressant mechanisms of action. Hum Psychopharmacol 2014; 29: 517-527

[45] Tabeshpour J, Sobhani F, Sadjadi SA, Hosseinzadeh H, Mohajeri SA, Rajabi O, Taherzadeh Z, Eslami S. A double-blind, randomized, placebocontrolled trial of saffron stigma (Crocus sativus L.) in mothers suffering from mild-to-moderate postpartum depression. Phytomedicine 2017; 36: $145-152$

[46] Tóth B, Hegyi P, Lantos T, Szakács Z, Kerémi B, Varga G, Tenk J, Pétervári E, Balaskó M, Rumbus Z, Rakonczay Z, Bálint ER, Kiss T, Csupor D. The efficacy of saffron in the treatment of mild to moderate depression: a meta-analysis. Planta Med 2019; 85: 24-31

[47] Khaksarian M, Behzadifar M, Behzadifar M, Alipour M, Jahanpanah F, Re TS, Firenzuoli F, Zerbetto R, Bragazzi NL. The efficacy of Crocus sativus (Saffron) versus placebo and fluoxetine in treating depression: a systematic review and meta-analysis. Psychol Res Behav Manag 2019; 12: 297305
[48] Kashani L, Eslatmanesh S, Saedi N, Niroomand N, Ebrahimi M, Hosseinian M, Foroughifar T, Salimi S, Akhondzadeh S. Comparison of saffron versus fluoxetine in treatment of mild to moderate postpartum depression: a double-blind, randomized clinical trial. Pharmacopsychiatry 2017; 50: 64-68

[49] Kashani L, Esalatmanesh S, Eftekhari F, Salimi S, Foroughifar T, Etesam F, Safiaghdam H, Moazen-Zadeh E, Akhondzadeh S. Efficacy of Crocus sativus (saffron) in treatment of major depressive disorder associated with post-menopausal hot flashes: a double-blind, randomized, placebo-controlled trial. Arch Gynecol Obstet 2018; 297: 717-724

[50] Milajerdi A, Jazayeri S, Shirzadi E, Hashemzadeh N, Azizgol A, Djazayery A, Esmaillzadeh A, Akhondzadeh S. The effects of alcoholic extract of saffron (Crocus sativus L.) on mild to moderate comorbid depressionanxiety, sleep quality, and life satisfaction in type 2 diabetes mellitus: A double-blind, randomized and placebo-controlled clinical trial. Complement Ther Med 2018; 41: 196-202

[51] Marx W, Lane M, Rocks T, Ruusunen A, Loughman A, Lopresti A, Marshall S, Berk M, Jacka F, Dean OM. Effect of saffron supplementation on symptoms of depression and anxiety: a systematic review and meta-analysis. Nutr Rev 2019; 77: 557-571

[52] Mazidi M, Shemshian M, Mousavi SH, Norouzy A, Kermani T, Moghiman T, Sadeghi A, Mokhber N, Ghayour-Mobarhan M, Ferns GA. A doubleblind, randomized and placebo-controlled trial of Saffron (Crocus sativus L.) in the treatment of anxiety and depression. J Complement Integr Med 2016; 13: 195-199

[53] Leone S, Recinella L, Chiavaroli A, Orlando G, Ferrante C, Leporini L, Brunetti L, Menghini L. Phytotherapic use of the Crocus sativus L. (saffron) and its potential applications: A brief overview. Phytother Res 2018; 32: 2364-2375

[54] Yang X, Chen X, Fu Y, Luo Q, Du L, Qiu H, Qiu T, Zhang L, Meng H. Comparative efficacy and safety of Crocus sativus $L$. for treating mild to moderate major depressive disorder in adults: a meta-analysis of randomized controlled trials. Neuropsychiatr Dis Treat 2018; 14: 1297-1305

[55] Jelodar G, Javid Z, Sahraian A, Jelodar S. Saffron improved depression and reduced homocysteine level in patients with major depression: A randomized, double-blind study. Avicenna J Phytomed 2018; 8: 43-50

[56] Dowlati Y, Herrmann N, Swardfager W, Liu H, Sham L, Reim EK, Lanctôt KL. A meta-analysis of cytokines in major depression. Biol Psychiatry 2010; 67: 446-457

[57] Lopresti AL. Cognitive behaviour therapy and inflammation: A systematic review of its relationship and the potential implications for the treatment of depression. Aust N ZJ Psychiatry 2017; 51: 565-582

[58] Esmaily H, Sahebkar A, Iranshahi M, Ganjali S, Mohammadi A, Ferns G, Ghayour-Mobarhan M. An investigation of the effects of curcumin on anxiety and depression in obese individuals: a randomized controlled trial. Chin J Integr Med 2015; 21: 332-338

[59] Bergman J, Miodownik C, Bersudsky Y, Sokolik S, Lerner PP, Kreinin A, Polakiewicz J, Lerner V. Curcumin as an add-on to antidepressive treatment: a randomized, double-blind, placebo-controlled, pilot clinical study. Clin Neuropharmacol 2013; 36: 73-77

[60] Lopresti AL, Maes M, Maker GL, Hood SD, Drummond PD. Curcumin for the treatment of major depression: a randomised, double-blind, placebo controlled study. J Affect Disord 2014; 167: 368-375

[61] Sanmukhani J, Satodia V, Trivedi J, Patel T, Tiwari D, Panchal B, Goel A, Tripathi CB. Efficacy and safety of curcumin in major depressive disorder: a randomized controlled trial. Phytother Res 2014; 28: 579-585

[62] Lopresti AL, Maes M, Meddens M], Maker GL, Arnoldussen E, Drummond PD. Curcumin and major depression: a randomised, double-blind, placebo-controlled trial investigating the potential of peripheral biomarkers to predict treatment response and antidepressant mechanisms of change. Eur Neuropsychopharmacol 2015; 25: 38-50

[63] Ng QX, Koh SSH, Chan HW, Ho CYX. Clinical use of curcumin in depression: a meta-analysis. J Am Med Dir Assoc 2017; 18: 503-508 
[64] Kanchanatawan B, Tangwongchai S, Sughondhabhirom A, Suppapitiporn S, Hemrunrojn S, Carvalho AF, Maes M. Add-on treatment with curcumin has antidepressive effects in Thai patients with major depression: results of a randomized double-blind placebo-controlled study. Neurotox Res 2018; 33: 621-633

[65] Panahi Y, Badeli R, Karami GR, Sahebkar A. Investigation of the efficacy of adjunctive therapy with bioavailability-boosted curcuminoids in major depressive disorder. Phytother Res 2015; 29: 17-21

[66] Al-Karawi D, Al Mammori DA, Tayyar Y. The role of curcumin administration in patients with major depressive disorder: mini meta-analysis of clinical trials. Phytother Res 2016; 30: 175-183

[67] Lopresti AL, Drummond PD. Efficacy of curcumin, and a saffron/curcumin combination for the treatment of major depression: A randomised, double-blind, placebo-controlled study. J Affect Disord 2017; 207: 188 196

[68] Lopresti AL. The problem of curcumin and its bioavailability: could its gastrointestinal influence contribute to its overall health-enhancing effects? Adv Nutr 2018; 9: 41-50

[69] Kaufmann FN, Gazal M, Bastos CR, Kaster MP, Ghisleni G. Curcumin in depressive disorders: An overview of potential mechanisms, preclinical and clinical findings. Eur J Pharmacol 2016; 784: 192-198

[70] Antony B, Merina B, lyer S, Judy N, Lennertz K, Joyal S. A pilot cross-over study to evaluate human oral bioavailability of BCM-95 CG (Biocurcumax), a novel bioenhanced preparation of curcumin. Indian J Pharm Sci 2008; 70: 445-4590

[71] Cuomo J, Appendino G, Dern AS, Schneider E, McKinnon TP, Brown M], Togni S, Dixon BM. Comparative absorption of a standardized curcuminoid mixture and its lecithin formulation. J Nat Prod 2011; 74: 664-669

[72] Raison CL, Capuron L, Miller AH. Cytokines sing the blues: inflammation and the pathogenesis of depression. Trends Immunol 2006; 27: 24-31

[73] Dantzer R, O'Connor JC, Lawson MA, Kelley KW. Inflammation-associated depression: from serotonin to kynurenine. Psychoneuroendocrinology 2011; 36: 426-436

[74] Maes M, Berk M, Goehler L, Song C, Anderson G, Gałecki P, Leonard B. Depression and sickness behavior are Janus-faced responses to shared inflammatory pathways. BMC Med 2012; 10: 66

[75] Lotrich FE. Inflammatory cytokine-associated depression. Brain Res 2015; 1617: 113-125

[76] Ghandadi M, Sahebkar A. Curcumin: an effective inhibitor of interleukin-6. Curr Pharm Des 2017; 23: 921-931

[77] Hannestad J, DellaGioia N, Bloch M. The effect of antidepressant medication treatment on serum levels of inflammatory cytokines: a meta-analysis. Neuropsychopharmacology 2011; 36: 2452-2459

[78] Eyre HA, Air T, Pradhan A, Johnston J, Lavretsky H, Stuart M], Baune BT. A meta-analysis of chemokines in major depression. Prog Neuropsychopharmacol Biol Psychiatry 2016; 68: 1-8

[79] Hewlings S], Kalman DS. Curcumin: a review of its' effects on human health. Foods 2017; 6: E92

[80] Derosa G, Maffioli P, Simental-Mendía LE, Bo S, Sahebkar A. Effect of curcumin on circulating interleukin- 6 concentrations: A systematic review and meta-analysis of randomized controlled trials. Pharmacol Res 2016; 111: 394-404

[81] Mantzorou M, Pavlidou E, Vasios G, Tsagalioti E, Giaginis C. Effects of curcumin consumption on human chronic diseases: A narrative review of the most recent clinical data. Phytother Res 2018; 32: 957-975

[82] Lopresti AL. Curcumin for neuropsychiatric disorders: a review of in vitro, animal and human studies. J Psychopharmacol 2017; 31: 287-302

[83] De Feudis FV. Ginkgo biloba Extract (EGb 761). From Chemistry to the Clinic. Wiesbaden: Ullstein Medical; 1998: 1-6

[84] Meston CM, Rellini AH, Telch MJ. Short- and long-term effects of Ginkgo biloba extract on sexual dysfunction in women. Arch Sex Behav 2008; 37 : 530-547
[85] Beaubrun G, Gray GE. A review of herbal medicines for psychiatric disorders. Psychiatr Serv 2000; 51: 1130-1134

[86] Ashton AK, Ahrens K, Gupta S, Masand PS. Antidepressant-induced sexual dysfunction and Ginkgo biloba. Am J Psychiatry 2000; 157: 836-837

[87] Waddell DL, Hummel ME, Sumners AD. Three herbs you should get to know. Am J Nurs 2001; 101: 48-53

[88] Kang BJ, Lee SJ, Kim MD, Cho MJ. A placebo-controlled, double-blind trial of Ginkgo biloba for antidepressant-induced sexual dysfunction. Hum Psychopharmacol 2002; 17: 279-284

[89] Wheatley D. Triple-blind, placebo-controlled trial of Ginkgo biloba in sexual dysfunction due to antidepressant drugs. Hum Psychopharmacol 2004; 19: 545-548

[90] Hemmeter U, Annen B, Bischof R, Brüderlin U, Hatzinger M, Rose U, Holsboer-Trachsler E. Polysomnographic effects of adjuvant Ginkgo biloba therapy in patients with major depression medicated with trimipramine. Pharmacopsychiatry 2001; 34: 50-59

[91] Linde K, Mulrow CD. St John's wort for depression. Cochrane Database Syst Rev 2000; (2): CD000448

[92] Linde K, Mulrow CD, Berner M, Egger M. St John's wort for depression. Cochrane Database Syst Rev 2005; (2): CD000448

[93] Linde K, Berner MM, Kriston L. St John's wort for major depression. Cochrane Database Syst Rev 2008; 4: CD000448

[94] Rahimi R, Nikfar S, Abdollahi M. Efficacy and tolerability of Hypericum perforatum in major depressive disorder in comparison with selective serotonin reuptake inhibitors: a meta-analysis. Prog Neuropsychopharmacol Biol Psychiatry 2009; 33: 118-127

[95] Szegedi A, Kohnen R, Dienel A, Kieser M. Acute treatment of moderate to severe depression with hypericum extract WS 5570 (St John's wort): randomised controlled double blind non-inferiority trial versus paroxetine. BM] 2005; 330: 503

[96] Fava M, Alpert J, Nierenberg AA, Mischoulon D, Otto MW, Zajecka J, Murck H, Rosenbaum JF. A double-blind, randomized trial of St John's wort, fluoxetine, and placebo in major depressive disorder. J Clin Psychopharmacol 2005; 25: 441-447

[97] Ng QX, Venkatanarayanan N, Ho CY. Clinical use of Hypericum perforatum (St John's wort) in depression: A meta-analysis. J Affect Disord 2017; 210: 211-221

[98] Russo E, Scicchitano F, Whalley B], Mazzitello C, Ciriaco M, Esposito S, Patanè $M$, Upton R, Pugliese $M$, Chimirri $S$, Mammì M, Palleria $C$, De Sarro G. Hypericum perforatum: pharmacokinetic, mechanism of action, tolerability, and clinical drug-drug interactions. Phytother Res 2014; 28: 643-655

[99] Kuo CH, Chou YC, Liao KC, Shieh C], Deng TS. Optimization of light intensity, temperature, and nutrients to enhance the bioactive content of hyperforin and rutin in St. John's wort. Molecules 2020; 25: 4256

[100] Zirak N, Shafiee M, Soltani G, Mirzaei M, Sahebkar A. Hypericum perforatum in the treatment of psychiatric and neurodegenerative disorders: Current evidence and potential mechanisms of action. I Cell Physiol 2019; 234: 8496-8508

[101] Sarris ], Kavanagh DJ, Byrne G, Bone KM, Adams ], Deed G. The Kava Anxiety Depression Spectrum Study (KADSS): a randomized, placebocontrolled crossover trial using an aqueous extract of Piper methysticum. Psychopharmacology (Berl) 2009; 205: 399-407

[102] Witte S, Loew D, Gaus W. Meta-analysis of the efficacy of the acetonic kava-kava extract WS1490 in patients with nonpsychotic anxiety disorders. Phytother Res 2005; 19: 183-188

[103] Darbinyan V, Aslanyan G, Amroyan E, Gabrielyan E, Malmström C, Panossian A. Clinical trial of Rhodiola rosea L. extract SHR- 5 in the treatment of mild to moderate depression. Nord J Psychiatry 2007; 61: 343-348 
[104] Dwyer AV, Whitten DL, Hawrelak JA. Herbal medicines, other than St. John's Wort, in the treatment of depression: a systematic review. Altern Med Rev 2011; 16: 40-49

[105] Mao JJ, Xie SX, Zee J, Soeller I, Li QS, Rockwell K, Amsterdam JD. Rhodiola rosea versus sertraline for major depressive disorder: A randomized placebo-controlled trial. Phytomedicine 2015; 22: 394-399

[106] Mao J], Li QS, Soeller I, Xie SX, Amsterdam JD. Rhodiola rosea therapy for major depressive disorder: a study protocol for a randomized, double-blind, placebo-controlled trial. J Clin Trials 2014; 4: 170

[107] Amsterdam JD, Panossian AG. Rhodiola rosea L. as a putative botanical antidepressant. Phytomedicine 2016; 23: 770-783

[108] Akhondzadeh S, Kashani L, Fotouhi A, Jarvandi S, Mobaseri M, Moin M, Khani M, Jamshidi AH, Baghalian K, Taghizadeh M. Comparison of Lavandula angustifolia Mill. tincture and imipramine in the treatment of mild to moderate depression: a double-blind, randomized trial. Prog Neuropsychopharmacol Biol Psychiatry 2003; 27: 123-127

[109] Nikfarjam M, Rakhshan R, Ghaderi H. Comparison of effect of Lavandula officinalis and venlafaxine in treating depression: a double blind clinical trial. J Clin Diagn Res 2017; 11: KC01-KC04

[110] Haybar H, Javid AZ, Haghighizadeh MH, Valizadeh E, Mohaghegh SM, Mohammadzadeh A. The effects of Melissa officinalis supplementation on depression, anxiety, stress, and sleep disorder in patients with chronic stable angina. Clin Nutr ESPEN 2018; 26: 47-52

[111] Jeong HG, Ko YH, Oh SY, Han C, Kim T, Joe SH. Effect of Korean red ginseng as an adjuvant treatment for women with residual symptoms of major depression. Asia Pac Psychiatry 2015; 7: 330-336

[112] Diaper A, Hindmarch I. A double-blind, placebo-controlled investigation of the effects of two doses of a valerian preparation on the sleep, cognitive and psychomotor function of sleep-disturbed older adults. Phytother Res 2004; 18: 831-836

[113] Stough C, Lloyd J, Clarke J, Downey LA, Hutchison CW, Rodgers T, Nathan PJ. The chronic effects of an extract of Bacopa monniera (Brahmi) on cognitive function in healthy human subjects. Psychopharmacology (Berl) 2001; 156: 481-484

[114] Stough C, Lloyd J, Clarke J, Downey LA, Hutchison CW, Rodgers T, Nathan PJ. The chronic effects of an extract of Bacopa monniera (Brah$\mathrm{mi})$ on cognitive function in healthy human subjects. Psychopharmacology (Berl) 2015; 232: 2427

[115] Stough C, Downey LA, Lloyd J, Silber B, Redman S, Hutchison C, Wesnes K, Nathan PJ. Examining the nootropic effects of a special extract of Bacopa monniera on human cognitive functioning: 90 day double-blind placebo controlled randomized trial. Phytother Res 2008; 22: 1629-1634

[116] Niu K, Hozawa A, Kuriyama S, Ebihara S, Guo H, Nakaya N, OhmoriMatsuda K, Takahashi H, Masamune Y, Asada M, Sasaki S, Arai H, Awata S, Nagatomi R, Tsuji I. Green tea consumption is associated with depressive symptoms in the elderly. Am J Clin Nutr 2009; 90: 16151622

[117] Rothenberg DO, Zhang L. Mechanisms underlying the anti-depressive effects of regular tea consumption. Nutrients 2019; 11: E1361

[118] Sayyah M, Sayyah M, Kamalinejad M. A preliminary randomized double blind clinical trial on the efficacy of aqueous extract of Echium amoenum in the treatment of mild to moderate major depression. Prog Neuropsychopharmacol Biol Psychiatry 2006; 30: 166-169
[119] Yamatsu A, Yamashita Y, Maru I, Yang J, Tatsuzaki J, Kim M. The improvement of sleep by oral intake of GABA and Apocynum venetum leaf extract. J Nutr Sci Vitaminol (Tokyo) 2015; 61: 182-187

[120] Firoozabadi A, Zarshenas MM, Salehi A, Jahanbin S, Mohagheghzadeh A. Effectiveness of Cuscuta planiflora Ten. and Nepeta menthoides Boiss. \& Buhse in major depression: a triple-blind randomized controlled trial study. J Evid Based Complement Altern Med 2015; 20: 94-97

[121] Black N, Stockings E, Campbell G, Tran LT, Zagic D, Hall WD, Farrell M, Degenhardt L. Cannabinoids for the treatment of mental disorders and symptoms of mental disorders: a systematic review and meta-analysis. Lancet Psychiatry 2019; 6: 995-1010. Erratum in: Lancet Psychiatry 2020; 7: e3

[122] Ferber SG, Namdar D, Hen-Shoval D, Eger G, Koltai H, Shoval G, Shbiro L, Weller A. The "entourage effect": terpenes coupled with cannabinoids for the treatment of mood disorders and anxiety disorders. Curr Neuropharmacol 2020; 18: 87-96

[123] Bangratz M, Ait Abdellah S, Berlin A, Blondeau C, Guilbot A, Dubourdeaux $M$, Lemoine $P$. A preliminary assessment of a combination of rhodiola and saffron in the management of mild-moderate depression. Neuropsychiatr Dis Treat 2018; 14: 1821-1829

[124] Müller D, Pfeil T, von den Driesch V. Treating depression comorbid with anxiety - results of an open, practice-oriented study with St John's wort WS 5572 and valerian extract in high doses. Phytomedicine 2003; 10 (Suppl. 4): 25-30

[125] Sarris J, Kavanagh DJ, Deed G, Bone KM. St. John's wort and Kava in treating major depressive disorder with comorbid anxiety: a randomised double-blind placebo-controlled pilot trial. Hum Psychopharmacol 2009; 24: 41-48

[126] Zhang J], Gao TT, Wang Y, Wang JL, Guan W, Wang YJ, Wang CN, Liu JF jiang B. Andrographolide exerts significant antidepressant-like effects involving the hippocampal BDNF system in mice. Int J Neuropsychopharmacol 2019; 22: 585-600

[127] Bartels C, Belz M, Vogelgsang J, Hessmann P, Bohlken J, Wiltfang J, Kosteve K. To be continued? long-term treatment effects of antidepressant drug classes and individual antidepressants on the risk of developing dementia: a German case-control study. J Clin Psychiatry 2020; 81: 19m13205

[128] National Center for Complementary and Integrative Health (NCCIH). St. John's wort and depression: in depth. Accessed February 3, 2021 at: https://www.nccih.nih.gov/health/st-johns-wort-and-depressionin-depth

[129] Guy A, Brown M, Lewis S, Horowitz M. The 'patient voice': patients who experience antidepressant withdrawal symptoms are often dismissed or misdiagnosed with relapse or a new medical condition. Ther Adv Psychopharmacol 2020; 10: 1-15

[130] Davies ], Read J. A systematic review into the incidence, severity and duration of antidepressant withdrawal effects: Are guidelines evidence-based? Addict Behav 2019; 97: 111-121

[131] Jordan SA, Cunningham DG, Marles RJ. Assessment of herbal medicinal products: challenges, and opportunities to increase the knowledge base for safety assessment. Toxicol Appl Pharmacol 2010; 243: 198 216

[132] Pennington K, Focking M, McManus CA, Pariante CM, Dunn MJ, Cotter DR. A proteomic investigation of similarities between conventional and herbal antidepressant treatments. J Psychopharmacol 2009; 23: 520-530 